\title{
Research and application of hydrostatic high pressure in tumor vaccines (Review)
}

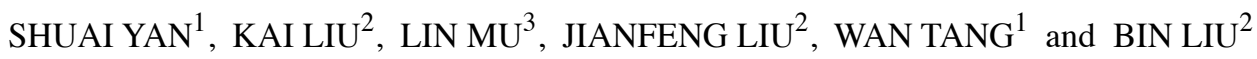 \\ Departments of ${ }^{1}$ Operating Room, ${ }^{2}$ Hand and Foot Surgery, and ${ }^{3}$ Radiology, \\ The First Hospital of Jilin University, Changchun, Jilin 130021, P.R. China
}

Received February 19, 2020; Accepted March 5, 2021

DOI: 10.3892/or.2021.8026

\begin{abstract}
It is well known that hydrostatic pressure (HP) is a physical parameter that is now regarded as an important variable for life. High hydrostatic pressure (HHP) technology has influenced biological systems for more than 100 years. Food and bioscience researchers have shown great interest in HHP technology over the past few decades. The development of knowledge related to this area can better facilitate the application of HHP in the life sciences. Furthermore, new applications for HHP may come from these current studies, particularly in tumor vaccines. Currently, cancer recurrence and metastasis continue to pose a serious threat to human health. The limited efficacy of conventional treatments has led to the need for breakthroughs in immunotherapy and other related areas. Research into tumor vaccines is providing new insights for cancer treatment. The purpose of this review is to present the main findings reported thus far in the relevant scientific literature, focusing on knowledge related to HHP technology and tumor vaccines, and to demonstrate the potential of applying HHP technology to tumor vaccine development.
\end{abstract}

\section{Contents}

1. Introduction

2. High hydrostatic pressure overview

3. Effects of high hydrostatic pressure on cells and biomacromolecules

4. High hydrostatic pressure and tumor vaccines

Correspondence to: Professor Bin Liu, Department of Hand and Foot Surgery, The First Hospital of Jilin University, 1 Xinmin Street, Changchun, Jilin 130021, P.R. China

E-mail:1_bin@jlu.edu.cn

Professor Wan Tang, Department of Operating Room, The First Hospital of Jilin University, 1 Xinmin Street, Changchun, Jilin 130021, P.R. China

E-mail: tangwan@jlu.edu.cn

Key words: hydrostatic high pressure, tumor vaccine, immunogenic cell death, dendritic cell, Annexin A5
5. High hydrostatic pressure and immunogenic cell death of tumors

6. High hydrostatic pressure and dendritic cell-based tumor vaccines

7. Tumor vaccines and Annexin A5

8. Conclusions and outlooks

\section{Introduction}

High hydrostatic pressure (HHP) is a traditional technology used to produce steel, alloys, ceramics, and synthetic materials (1). Over the past few decades, HHP has also been used for non-heat pasteurization of processed foods, designed to extend the storage time of foods, such as juice, milk, and canned products (2). As researchers in different scientific fields continue to explore HHP, some new applications of the technology are emerging $(3,4)$. Since most practical applications of HHP technology are subjecting biological systems to hydrostatic pressure (HP), the uniqueness of this method is currently being investigated at various levels, ranging from viruses, enzymes, microorganisms, mammalian cells, and tissues (5-7). Usually, all pressures are causing a reduction in the volume of the system, which can lead to changes in its structure and disturb the equilibrium of chemical reactions (8). Excessive pressure may lead to the destruction of cell structure (9). For numerous thermophilic microorganisms, HP inhibits cell growth in the range of tens of megapascal (MPa) and completely inhibits cell growth at approximately $50 \mathrm{MPa}(10)$. Pressure greater than $200 \mathrm{MPa}$ can annihilate most microorganisms (11).

Cancer poses a huge threat to human health. Currently, the main cancer treatments are surgery, radiation therapy (RT), and chemotherapy (CT). Multimodal treatment strategies may be effective in reducing tumor size, regressing solid tumors, and extending patient life (12). However, the recurrence and metastasis of tumors gives rise to a poor prognosis for numerous patients (13). Therefore, the goal of oncology treatment is not only to exterminate tumor cells of the primary origin but also to obtain long-lasting antitumor effects in order to control metastatic and recurrent tumor cells. However, these treatments currently leave much to be desired in terms of providing sustained antitumor effects and limiting tumor metastasis and recurrence. In addition to these disadvantages, these treatments have numerous toxic side effects that affect 
normal tissues (14). Combining the antitumor effects of the body with the host immune system to generate an effective antitumor immune response is an attractive therapeutic approach.

Tumor vaccines are designed to specifically activate the immune system of patients (15). Therefore, it is necessary to activate the immune response of patients to the tumor. The immune system must be trained to control dormancy and metastasis of residual tumor cells (16). Tumor vaccines may bypass the complex processes of defining individual antigens. There are numerous associated antigens on the surface and inside the tumor cells that prevent tumors from escaping immunity (17). To enhance the antitumor immune response, additional application of immune adjuvants is beneficial (18). The combination of conventional therapies with immunotherapy may improve the overall patient survival. In addition, immunotherapy may be more appropriate for oncology patients because of its lower toxicity compared to CT.

HHP technology is an effective approach to the production of tumor vaccines. Helmstein reported the application of HHP for the treatment of bladder cancer in 1972 (18). The patients were treated with hydrostatic bladder dilation. Subsequently, some authors reported that vaccination of HHP-treated tumor cells treated with the chemical cross-linker adenosine dialdehyde alone or in combination with the reducing agent $\mathrm{N}$-acetyl-L-cysteine induced antitumor immunity in vivo (19) and in vitro (20). In this review, we summarized the latest knowledge on the relevance of hydrostatic hypertension for immunotherapy of biomolecules and tumors and discussed possible future directions for the development of HHP tumor vaccines.

\section{High hydrostatic pressure overview}

The physical property of pressure is defined as the force per unit area acting on the surface in a direction perpendicular to the surface: $\mathrm{P}=\mathrm{F} / \mathrm{A}$ in which $\mathrm{P}$ represents the pressure, $\mathrm{F}$ represents the normal force applied to the surface, and A represents the area of the surface. The official unit of pressure is the Pascal ( $\mathrm{Pa})\left(1 \mathrm{~Pa}=1 \mathrm{~N} / 1 \mathrm{~m}^{2}=10^{-5}\right.$ bar $)$. The Newton represents a small force, while $1 \mathrm{~m}^{2}$ corresponds to a large surface, thus the Pascal is a very small unit of pressure. Therefore, $\mathrm{MPa}$ ( $1 \mathrm{MPa}=10^{6} \mathrm{~Pa}=10 \mathrm{~atm}$ ) is a common unit of pressure used in HP research. The conversion from $\mathrm{MPa}$ to other units of pressure is presented in Table I (21).

The first research on HP traces back to the late 19th century and was carried out mainly by oceanographers and physiologists (22). HP exists in all the explored biological environments. The pressure extends from 0.1 $\mathrm{MPa}$ (atmospheric pressure) at the sea level to $110 \mathrm{MPa}$ at the deepest part of the ocean in the Mariana Trench, $11 \mathrm{~km}$ below sea level (23). The average depth of the ocean is $3.8 \mathrm{~km}$. The average pressure on various marine organisms is approximately $38 \mathrm{MPa}$, which is 380 times the atmospheric pressure (24).

Roger first reported the use of HP technology to kill microorganisms such as Staphylococcus aureus and Escherichia coli in 1895 (25). Hite (26) and Hite et al (27) studied microbial inactivation in milk using $650 \mathrm{MPa} \mathrm{HHP}$ technology in 1899 and developed microbial inactivation for extended storage of vegetables and fruits in 1914. From 1932 to 1952, some researchers studied HHP technology to inactivate the different microorganisms for food processing and biological applications. For example, they studied the effects of HHP on bacteria (28), viruses $(29,30)$, antigens (31), antibodies (31), and tumors (32). The effects of HHP technology on macromolecular and eukaryotic physiological processes have been extensively studied since the middle of the 20th century, mainly using sea urchins and frog eggs (33-35), as well as epithelial cells, chondrocytes, and tumor cells (36-38). In the early 1990s, HHP technology was further developed in Japan and used for the processing and preservation of food products without the thermal treatment and the addition of preservatives (39), since it does not affect vitamins and pharmacologically active molecules and does not change flavors and aromas (40). In addition to food sterilization and preservation, HHP technology has been widely used in numerous other applications (41). In the biotechnological and pharmaceutical industries, HHP technology is also used in the sterilization of bone grafts and in the development of tumor vaccines, all of which take advantage of the molecular effects of HHP (41).

\section{Effects of high hydrostatic pressure on cells and biomacromolecules}

Over the past few decades, a growing number of disciplines have begun to explore the potential of exposing a variety of complex biological units to HHP, including proteins, lipids, nucleic acids, eukaryotic cells, and multicellular tissues (41). In general, all pressure effects correspond to a reduction in the volume of the biological unit and the acquisition of a more compact structure (8). The aforementioned will be discussed in more detail in the later sections.

Effects of high hydrostatic pressure on cells. HP is one of the physical factors that affect cellular physiology. Inappropriate pressure can lead to inhibition of cell growth, structural destruction of cells, and cell death. HHP between 1 and $100 \mathrm{MPa}$ is considered non-lethal, which leads to reversible morphological changes and slight stress response. HHP between 100 and $150 \mathrm{MPa}$ can induce the apoptosis of murine cells. HHP between 150 and $250 \mathrm{MPa}$ can affect the viability of human cells, while pressures between 300 and $400 \mathrm{MPa}$ can lead to cell necrosis $(41,42)$. During HHP treatment inactivation, the pressure is instantaneously and uniformly distributed throughout the non-toxic media and can be transmitted through all flexible packaging materials. Each part of the treated sample is subjected to the same pressure simultaneously (43). Finally, each treated cell in the system is exactly subjected to the same stress and extremely high reproducibility can be achieved (44). Pressure will penetrate the cell instantly and completely, thus applying it to the entire intracellular components (44). It is assumed that exposing cells to pressures above a certain threshold will result in a progressive increase in membrane rigidity and protein denaturation, which will eventually lead to cell death (43) (Fig. 1).

Some studies have reported apoptosis as well as necrosis of cells after non-physiological HHP exposure, with the specific mechanism of cell death mainly depended on the sensitivity of the cell type and the pressure level $(45,46)$. Cell death occurs through apoptosis at pressures of approximately $200 \mathrm{MPa}(47)$, and cell necrosis occurs at pressures $>300 \mathrm{MPa}(23,24,47)$. 
Table I. Conversion of the different units of pressure.

\begin{tabular}{|c|c|c|c|c|c|}
\hline Units of pressure & Atmosphere & $\mathrm{MPa}$ & $\mathrm{kg} / \mathrm{cm} 2$ & Bar & P.S.I. (pound/inch ${ }^{2}$ ) \\
\hline Atmosphere & 1 & 9.901 & 0.968 & 0.987 & 0.068 \\
\hline Mpa & 0.101 & 1 & 0.098 & 0.1 & 0.00689 \\
\hline $\mathrm{kg} / \mathrm{cm}^{2}$ & 1.033 & 10.228 & 1 & 1.021 & 0.070 \\
\hline Bar & 1.013 & 10.000 & 0.981 & 1 & 0.069 \\
\hline P.S.I. (pound/inch ${ }^{2}$ ) & 14.696 & 145.038 & 14.223 & 14.504 & 1 \\
\hline
\end{tabular}

MPa, megapascal; P.S.I., pounds per square inch.

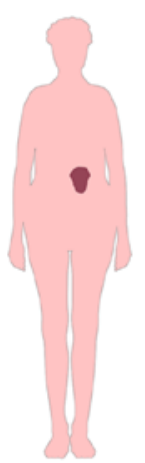

Patient
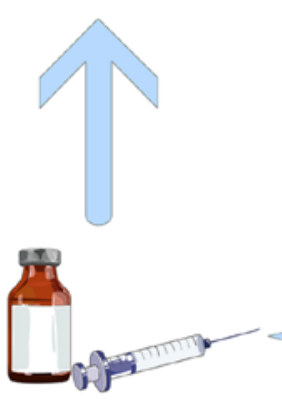

Tumor vaccine

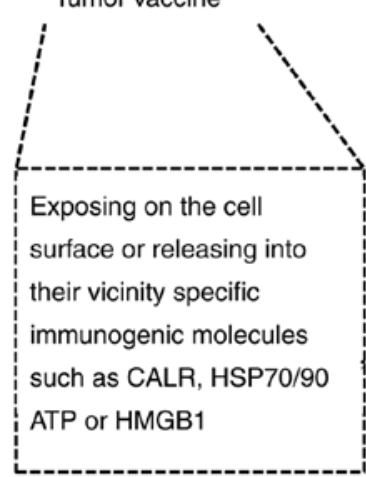

Biopsy removal of

tumor tissue
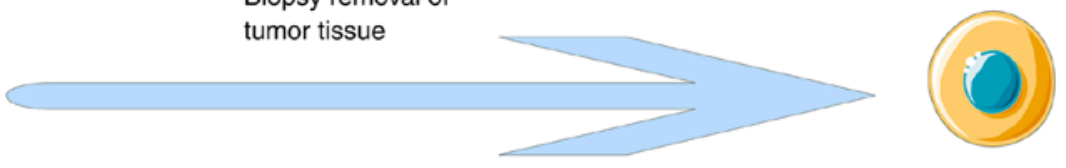

Tumor cell

Properties of HHP treatment:

1. Pressure propagates with a velocity

to sound velocity in the media.

2. Force-vector of pressure acts

orthogonal to all the surfaces.

3. Pressure propagates through the flexible wrappings.

Figure 1. Characterization of HHP treatment and its effects on tumor cells. HHP treatment effectively induces tumor cell killing and is considered a novel method for the preparation of autologous tumor cell vaccines from the tumor tissue obtained from biopsies or surgery. ATP, adenosine triphosphate; CALR, calreticulin; ER, endoplasmic reticulum; HHP, high hydrostatic pressure; HMGB-1, high mobility group box 1; HSP, heat shock protein.

Liu et al used HHP to inactivate B16-F10 melanoma cells at different pressures $(\geq 50 \mathrm{MPa})$ and for different durations ( $\geq 1 \mathrm{~min}$ ) (48). Their results suggested that HHP may be an effective measure for the preparation of melanoma vaccines when the pressure was $\geq 200 \mathrm{MPa}$ and the treatment duration was $\geq 30 \mathrm{~min}$. Seitz et al demonstrated that in vitro treatment at $200 \mathrm{MPa}$ or higher completely inhibited the formation of tumor cell colonies and that HHP produced inactivated tumor cells that could be used as a tumor vaccine (49). Similarly, they demonstrated synergy between tumor cell-based vaccines and RT, significantly hindering tumor growth by generating a favorable antitumor immune microenvironment.

HHP-induced apoptosis occurs through the activation of caspase- 3 by extrinsic and intrinsic pathways. The extrinsic 
pathway is characterized by the binding of the Fas ligands to the cell death receptor Fas on the cell surface (50). Cytochrome $c$ is frequently released from mitochondria into the cytoplasm when the intrinsic pathway is activated (47). Apoptosis leads to cell death through cell shrinkage, loss of microvilli, and chromatin condensation (47). The clearance of apoptotic cells is mediated by 'find-me' signals released by apoptotic cells to facilitate the clearance of apoptotic cells by phagocytes (51). Phagocytes recognize the 'eat me' signals on the surface of apoptotic cells and rapidly clear them. Clearance of apoptotic cells stimulates activated phagocytes, which secrete anti-inflammatory signals such as transforming growth factor- $\beta$ (TGF- $\beta$ ) and interleukin-10 (IL-10) (52). However, it has been revealed that apoptosis may also exhibit immune-stimulatory features under certain circumstances, especially when treated with $\gamma$-irradiation or certain CT drugs (anthracyclines) (53). Cell necrosis occurs in HHP above $300 \mathrm{MPa}$ (24). The onset of cellular necrosis is not dependent on the activation of caspases. Cellular necrosis leads to cell swelling, organelle degradation, especially irreversible mitochondrial damage, and changes in intracellular ionic concentrations. These changes ultimately lead to the damage of cell membranes and the release of inflammatory cellular inclusions (47). However, it is not entirely clear to what extent the molecular nature of the danger signals of passive exposure of necrotic tumor cells overlaps with immunogenic apoptosis.

Apoptotic cells in the physiological state are immune-silent or tolerogenic. They are part of the physiological processes that maintain homeostasis in multicellular organisms (54). Apoptosis is characterized by some cellular morphological and biochemical features, such as blistering, chromatin condensation, and DNA fragmentation (55). In contrast to apoptosis, cell necrosis is associated with inflammation, which is controlled by pathological processes (56). Extracellular high mobility group box 1 (HMGB1) and heat shock proteins (HSPs) are typical examples of such released immune activator proteins (57). In addition, apoptotic and necrotic cells can also release some other danger signals (58). The loss of cell membrane integrity leads to the release of danger signals, which can lead to the activation and maturation of immune cells and often generate inflammation (58). It must be taken into consideration that in the case of apoptosis, the danger signals are modified before the secretion, resulting in the opposite immunological outcome (59). For instance, HMGB1 is generally oxidized by reactive oxygen species (ROS) during apoptosis and thus loses its immune potency (60). This suggests that dying cells and their microenvironment determine whether the immune activation or the immunosuppression is induced.

The forms of cellular death are manifold and sometimes indistinguishable. Some studies have also focused on the cell death pattern after HHP treatment. Dead cells are potent modulators of the immune system, and the immunogenicity of the treated cells depends largely on the death-inducing stimulus $(61,62)$. In the syngeneic condition, live and normal apoptotic cells do not drive immune responses or lead to anti-inflammation (52). In stark contrast, necrotic cells induce immune responses (63). However, inactivation processes that induce necrosis in vitro usually do not exhibit favorable immunogenic responses in vivo. The immunogenicity of treated cells is highly dependent on the death-initiating stimulus and must be analyzed separately (61).
Finally, the treatment processes must be carried out in highly repeatable manners and meet all legal requirements.

Effects of high hydrostatic pressure on biomacromolecules. Pressure, similar to temperature, is an important thermodynamic parameter that can profoundly affect molecular systems (64). HHP represents a distinctive form of stress associated with volume changes that alter numerous physiological and biochemical processes, such as protein unfolding and dissociation, lipid bilayer phase transition, and ligand binding $(65,66)$. Pressure studies on biomolecules are generally performed between 0.1 and 1,500 MPa (23). In cells, HHP mainly affects the non-covalent bonds of biomacromolecules, such as proteins and lipids (23). The HHP of approximately $200 \mathrm{MPa}$ mainly alters the tertiary and quaternary structure of proteins, which leads to disruption of the enzymatic function. Under this pressure, the primary structures of proteins can remain intact. When the HHP is $>400 \mathrm{MPa}$, the protein is rapidly denatured (67). HHP transforms the conformation of phospholipid bilayers from fluid-crystalline type to gel-like type (68). Mitochondrial activity is associated with important functions for cell growth. For example, the polymerization of actin filaments and the conversion of adenosine triphosphate (ATP) (69). Therefore, HHP treatment of approximately $200 \mathrm{MPa}$ will induce cell killing by inactivating mitochondrial activity (7). Furthermore, DNA may be resistant to non-physiological HHP at approximately 1,000 MPa because its secondary structure is mainly stabilized by $\mathrm{H}$-bonds, which are practically insensitive to HHP in biotechnology (70). Only HHP >1,000 MPa can induce the transition from double-stranded DNA to single-stranded DNA. The effects of different pressure levels on cells and biomacromolecules are presented in Fig. 2.

Effects of high hydrostatic pressure on protein. In 1914, Bridgman studied the coagulation of albumen under the pressure (71). However, Grant explained this phenomenon as the protein denaturation phenomenon in 1941 (72). HHP is known to denature proteins and it does not affect covalent bonds, which signifies that the primary and secondary structures of proteins are preserved while the tertiary and quaternary structures are changed (73). Perreault et al indicated that for some types of proteins there may be a partial or complete loss of efficiency after HHP treatment (67). HHP disrupts non-covalent chemical bonds, which are essential for maintaining the structure and function of proteins. These changes are sufficient to affect the binding, stability, and catalytic sites of the polymers. Therefore, the structures and functions of proteins may be altered during the compression (74).

The absorption of amino acids is also sensitive to HHP. Effects of HHP on amino acid uptake is attributed to the impairment of amino acid permeases and transport proteins at the cell surfaces (75). Generally speaking, $200 \mathrm{MPa}$ HHP treatment completely induced cell killing by inactivating the enzymatic activity in mitochondria (76). As is well known, the mitochondria are associated with the polymerization of actin filaments and the supply of cellular energy (77). Significant advances have been made in our knowledge of cellular piezoelectric physiology $(78,79)$. Given its effect on proteins, it is not surprising to reveal that sublethal HHP can induce the expression of HSPs in both prokaryotic and eukaryotic cells (80). 


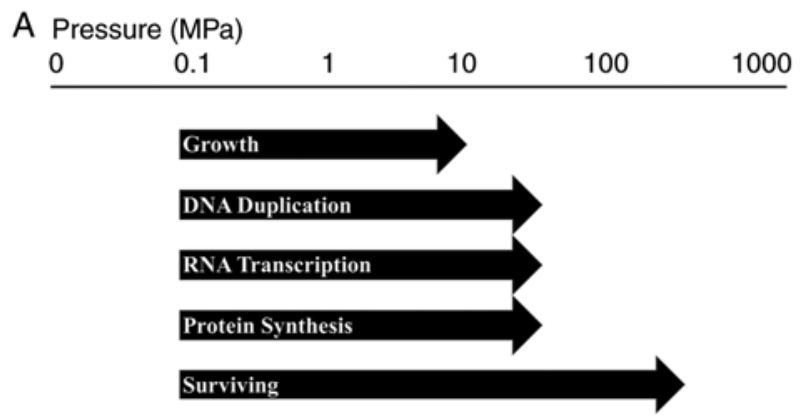

B Pressure (MPa) 0200 500 1000
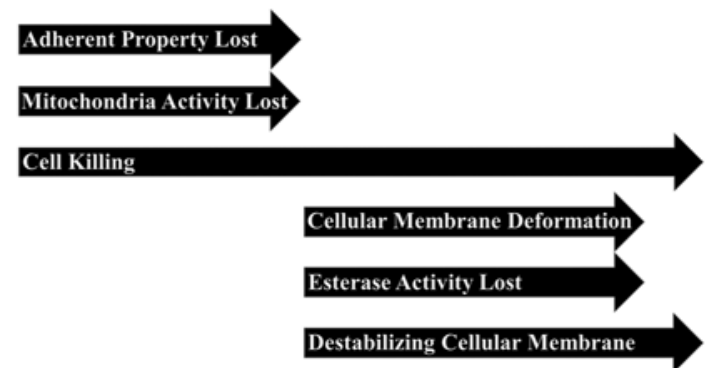

Figure 2. (A) HHP reduces the ability for growth, DNA replication, RNA transcription, protein synthesis, and survival. The arrows show the highest limits of these capacities. (B) Schematic image of the effect of the pressure treatment on the process of cell killing. At HHP below $200 \mathrm{MPa}$, the treated cells have adhered. When cells are treated with HHP above $200 \mathrm{MPa}$, the high pressure induces increased cell permeability, cell inactivation, and leads to cell killing. HHP, high hydrostatic pressure; MPa, megapascal.

The ribosomes are decomposed by HHP due to the decomposition of polymorphs caused by pressure $(70 \mathrm{~S} \rightarrow 30 \mathrm{~S}+50 \mathrm{~S})(81,82)$. The dissociation of uncharged ribosomes is accompanied by a large negative volume change. The dissociation of ribosomes appears to be one of the main factors leading to cell death by HHP treatment, as cells cannot survive when the quantity of functional ribosomes drops below a threshold (81).

Effects of high hydrostatic pressure on lipid. Lipid membranes are the most pressure-sensitive biological components due to their high compressibility and fluidity (83). The lipid components of biological membranes have usually been visualized as a physical homogeneous system. However, there is growing evidence that lipid domains of different compositions and structures may exist in biological membranes even at the physiological temperature $(84,85)$. Changes in pressure will lead to changes in the structures and sizes of these domains as well as in the functional state of the membrane. The low pressures can change the local composition of biological membrane lipid domains, which have significant biochemical implications (86). In general, the maintenance of basic physiological functions of biological membranes requires the dynamic and structural properties of cell membranes. Manisegaran et al reported that HHP and low temperature have a strong influence on lipid biological membranes, mainly because they both affect the fluidity of biological membranes to a large extent, leading to tight packing and limiting acyl-chain movement (86).

The compression of the phospholipid bilayer is usually anisotropic. Under HHP conditions, the acyl-chain straightening leads to lateral contracting and increased thickness. This phenomenon is also accompanied by a phase transition from the liquid crystal to the gel phase (87). As pressure increases, lipid bilayers lose fluidity and rapidly become impermeable to water and other molecules, while protein-lipid interactions essential for optimal functions of the biological membranes become weaker (87). In addition to altering fluidity, HHP also changes the compositions of lipid membranes by increasing the content of unsaturated fatty acids. This corresponds to an adaptive mechanism of increased fluidity, which is thought to be because unsaturated fatty acids require less carbon and energy to achieve similar results in membrane fluidity compared to saturated fatty acids (88).

Due to the sensitivity of lipids to HHP, these biological components are usually considered as the main targets of cellular and microbial stress inactivation (87). Membrane potential also decreases with increasing pressure until $400 \mathrm{MPa}(89)$. These results support that the properties of cellular membranes are related to the cell-killing activity of the treatment. However, cell membrane damage induced by HHP may not be the critical factor for the cell killing, as 400-500 $\mathrm{MPa}$ of pressure is required to induce the damage of the cell membranes, but $200 \mathrm{MPa}$ of pressure is sufficient to kill cells. Pressure treatment decreases the enzymatic and metabolic activity (90). It is considered that deep-sea creatures have evolved special membranes and membrane proteins to adapt to such extreme circumstances. A variety of organisms can compensate for the packing effects of biological membranes by modifying compositions of fatty acids (86). Cold adaptation is usually associated with the binding of the unsaturated bonds within the acyl chains (91). Acyl chains on biological membranes containing unsaturated bonds have larger conformations than their saturated counterparts, thus allowing greater conformational freedom and less packing of the biological membrane. Consequently, the biological membrane becomes more fluid. Sinensky reported that this adaptation by creatures living in cold and high-pressure environments has been known as homeoviscous adaptation (92). Whether homeoviscous adaptation universally occurs in deep-sea creatures remains unknown, as the properties of natural biological membranes responding to HHP have not been fully studied.

HHP may change the fluidity of membranes and indirectly affect the binding or conformation of signaling molecules (93). HHP can also change forces within the membranes by increasing the bending rigidity to produce biological forces sufficient to trigger the mechano-chemical responses (94). The direct lethal effects of HHP may include biological membrane damage and other undefined fast-acting responses, and ROS production due to biological membrane damage may continue even after the treatment. Atmospheric oxygen may promote ROS production by oxidases located in the damaged biological membrane of HHP-treated cells. HHP can trigger metabolic disorders that generate ROS in treated cells, which can eventually damage their viability (95).

Effects of high hydrostatic pressure on nucleic acid. Typically, HHP below 1,000 MPa cannot affect DNA, while pressure treatments above $1,000 \mathrm{MPa}$ may result in DNA alterations (24). As stress increases, double-stranded DNA becomes more stable, so processes such as replication, 
transcription, and translation become more difficult. The transition from double-stranded to single-stranded is essential for cell survival (96). However, Macgregor revealed that the clear transition from the double-stranded DNA to the single-stranded DNA can be observed below 1,000 MPa (96).

Chromosomal DNA has been considered stable generally (97), and in vivo exposure to HHP often affects DNA integrity indirectly by triggering mobilization of genetic elements (98), different methylation patterns (99), or strand breaks (100). When the cell necrosis is induced by stimuli such as hydrogen peroxide or heat, degraded DNA strands are uncommon (45). However, Frey et al found that HHP treatment did not inactivate $\mathrm{Ca}^{2+}$-dependent DNA enzymes, which led to further degradation of DNA strands in cells that had already lost the integrities of membranes (45). During the analysis of the nucleic acid content of cells treated with $200 \mathrm{MPa}$, it was revealed that the content of degraded sub-G1 DNA increased during the post-treatment culture. This result suggests that the DNA degradation is the result of DNA fragmentation during the apoptosis rather than as an effect induced directly by HHP treatment (101). Cellular processes or structures that are impaired by HHP treatment are presented in Table II (102).

\section{High hydrostatic pressure and tumor vaccines}

Cancer immunotherapy (CI), particularly when used in combination with other therapies such as RT and CT, is a promising avenue to cancer treatment. Shi et al have demonstrated the synergistic effects of the combination of CI and CT in the clinical study (103). CI stands out in the second-line treatment for recurrent tumors and metastases by activating the immune systems of patients to trigger an antitumor response (103). Since tumor recurrence and metastasis remain the main reasons for tumor-related deaths, the identification of tumor cell specificity and persistence will be the focus of future research. To date, the number and type of specific T cells required for the efficient antitumor therapy are unknown (104). Although different subtypes of immune cells are suspected to have various effects on tumor progression, the infiltration of immune cells is usually associated with the prognosis of most solid tumors $(105,106)$. Therefore, CI is a suitable adjuvant to standard tumor therapies because it is designed to activate the immune system of the patient against tumor cells (107).

When developing multimodal concepts for tumor therapy, the treatment methods of tumor vaccines should be considered (108). Vaccination is an agent that causes the host to receive treated autologous tumor cells in order for a large number of defined tumor antigens to simultaneously stimulate the immune system of the host (109). HHP inactivation of tumor cells can be performed in a highly repeatable manner according to Good Manufacturing Practices (GMP) and legal requirements. These vaccines must also fulfill the major requirements for all cell-based therapeutic tumor vaccines, including i) complete inactivation of tumor cells, ii) maintenance of immunogenicity, and iii) compliance with statutory provisions (110). Physical (X-ray and freeze-thawing) and chemical methods have been used to inactivate tumor cells in vaccination experiments (46). However, these methods usually have some restrictions. Tumor cells cannot be inactivated safely by a mild treatment, or the inactivated cells are
Table II. Cellular processes or structures impaired by the high hydrostatic pressure.

\begin{tabular}{lc}
\hline Cellular process or structure & $\begin{array}{c}\text { Inhibitory } \\
\text { pressure (MPa) }\end{array}$ \\
\hline Motility & 10 \\
Nutrient absorption & $15-20$ \\
Cell division & 20 \\
The function of membrane protein & $25-50$ \\
Replication & 50 \\
Protein synthesis & 50 \\
Transcription & $50-100$ \\
Protein oligomerization & $50-100$ \\
The function of soluble enzymes & 100 \\
Viability & $100-200$ \\
The monomer of protein structure & 200 \\
The double helix of DNA structure & 1,000 \\
\hline
\end{tabular}

MPa, megapascal.

weakly immunogenic (46). HHP fulfills these specifications for clinical vaccine: It inactivates tumor cells effectively, is non-toxic, does not wreck the immunogenicity of the tumor cells, and can comply with GMP and legal requirements. In additiom, it is a repeatable and easy to apply method (111). Therefore, HHP treatment is superior to other methods, such as freeze-thaw, radiation, or heat killing methods. Furthermore, the HHP approach cannot mix other chemicals into tumor vaccines, unlike the chemical methods (49). These advantages suggest that HHP is a promising method for generating tumor vaccines (112).

The use of HHP in tumor inactivation and tumor vaccine development has been studied since the 1970s (113). In 1972, HHP was reported as the tumor treatment method and was investigated for the treatment of bladder cancer by using the hydrostatic bladder dilatation method (18). Later, Deckmann et al reported that treatment of leukemic cells with $150 \mathrm{MPa}$ HHP resulted in enhanced immunogenicity (114). Since then, HHP has been used to inactivate tumor cells to develop vaccines. Eisenthal et al treated tumor cells with HHP (120 MPa) in the presence of the biocompatible crosslinker, adenosine dialdehyde (115). Treated cells were potent immunogens because HHP increases the antigenic presentation by rearranging the cell surface proteins into immunogenic clusters (118). This study indicated that HHP-killed tumor cells can trigger antitumor immune responses. This syngeneic tumor vaccine that mimics the autologous vaccine from their tumor cells should contain all relevant tumor-associated antigens (TAAs) that may target a specific patient (116).

The purpose of tumor vaccines is to train the immune system to actively develop lasting immune memory to fight the metastasis and recurrence of tumors (117). Weiss et al concluded that the inactivation of intact tumor cells induced by HHP, the degradation of the nucleus, and the preservation of the immunogenic potential of these dead tumor cells facilitate the use of this technology for the production of tumor 
vaccines (46). Frey et al have also revealed that HHP-treated tumor cells can preserve their shapes for more than a few weeks, which appears to be important for the production of potent vaccines (24). HHP treatment also caused a marked increase in cytoplasmic viscosity of the treated cells, which would lead to a slow and sustained release of cell-derived antigens and danger signals (45). These features are critical for the phagocytosis of tumor cells and subsequent presentation of cognate antigens by dendritic cells (DCs), and further expand the prospects of applying HHP technology to produce tumor vaccines (118).

Notably, HHP-induced cell necrosis occurs simultaneously with cytoplasmic gelation, and these cellular particles appear to maintain the relevant immunogenicity (42). Frey et al have proposed the use of HHP-treated tumor cells as the whole-cell-based tumor vaccines, due to the preservation of the antigenicity (24). Moserova et al revealed that HHP treatment could induce immunogenic cell death in tumor cell lines and revealed some molecular mechanisms associated with this phenomenon (119). Apoptosis induced by HHP treatment was controlled by the overproduction of ROS, which caused a rapid establishment of an integrated stress response and subsequent activation of caspase- 2 , caspase- 3 , and caspase- 8 activation in dying tumor cells (119). Traditionally, apoptosis is considered immunologically silent, but specific immunogenic molecules, such as calreticulin, adenosine-triphosphate (ATP), HSP 70/90, or HMGB1, are released at or near the cell surfaces, thereby activating immune cells to enhance their antitumor activity $(119,120)$.

Processing of tumor cells by HHP promotes the production of ROS. The processing of cells by pressure triggers downstream signaling pathways, such as cleavage of caspase-2, caspase-3, and caspase-8 (121). Moserova et al reported the application of various ROS scavengers and indicated that for HHP-induced calreticulin, the production of ROS was one of the prerequisites (119). More specifically, HHP-mediated ROS production may affect endoplasmic reticulum (ER) homeostasis, further triggered the phosphorylation of extension initiation factor (eIF)-2 $\alpha$ and the cleavage of caspase-2, which was important for HHP-induced danger signaling involving calreticulin induction (122). Sandow et al have revealed that ER stress and ROS production may or may not lead to caspase-2 cleavage, depending on the prevailing environment (123). In addition, specific antibody blockade of calreticulin or depletion of caspase-2 significantly inhibited DC phagocytosis (119). While it remained unclear how caspase-2 regulated the exposure of calreticulin, the localization of this caspase in the ER and Golgi systems suggested the possible involvement in regulating the transit mechanisms (124). However, inhibition of ROS production was not sufficient to eliminate HHP-induced calreticulin exposure, suggesting that ROS-independent mechanisms may also be involved in this process. Therefore, exogenous calreticulin is important for the phagocytosis of tumor cells and the induction of specific immune responses in vaccine patients (125).

In previous studies, HHP technology was identified as an inducer of antitumor immunity in a variety of tumor cell lines (126-128). Due to its immunogenicity, this physical modality has been standardized and validated for incorporation into the manufacturing process of tumor immunotherapy products (129). In numerous cases, it was not possible to obtain autologous malignant cells from patients due to the inoperability of the tumor. The number of malignant cells in the biopsy or resected tumors was too small to produce a vaccine for the repeated administration during the immunotherapy. The HHP-killed tumor cell lines also retained an abundance of specific or tumor-associated antigens, which represented an advantage of this approach over numerous vaccines, where the number of antigens is often limited (130). Autologous tumor cells are a suitable source of antigens for vaccination. Providing an antigen array on the cell surface reduces the risk of tumor immune escape and eliminates the need to define individual antigens (131).

The advantages of vaccines based on autologous whole tumor cells are that they do not have to prospectively identify target antigens and can provide numerous TAAs that aberrantly express autoantigens. In contrast to neoantigens, the latter should only activate remaining low-affinity $\mathrm{T}$ cells and have to overcome the self-tolerance (132). Several additional methods have been developed to address the barrier, such as the addition of adjuvants, repeated vaccination, or co-stimulation (104). HHP-treated whole-cell-tumor vaccines have the advantage of providing multiple antigens and therefore lead to better results. This approach has been demonstrated in clinical trials in multiple myeloma (133) or renal cell carcinoma (134). Therefore, the inactivated form of whole tumor cells used as a vaccine, as well as the cell death induced in the primary tumor by standard methods, is important for triggering the effective antitumor immunity.

\section{High hydrostatic pressure and immunogenic cell death of tumors}

Large numbers of treated apoptotic tumor cells have been shown to trigger an effective antitumor immune response in mice (135). Galluzzi et al reported two morphologically equivalent but immunologically distinct subcategories of apoptosis, immunogenic and non-immunogenic apoptosis, thus introducing the concept of immunogenic cell death (ICD) (112). ICD was primarily mediated by defined spatiotemporal release or exposure of relevant danger signals or the damage-associated molecular patterns (DAMPs), which could act as adjuvants or associated danger signals to the innate immune system to trigger host protective antitumor immunity (136). Recently, several DAMPs have been associated with ICDs, where surface exposure of the ER-resident chaperone calreticulin was one of the main checkpoints for determining cellular immunogenicity (137). McDaniel et al reported that tumor cell ICDs were characterized by induction of ER stress response, production of ROS, and release of danger-related molecules, such as calreticulin, HSP, HMGB1, or ATP (138). Several tumor chemotherapies and cell physical death-inducing modalities have been described to induce ICD of tumor cells (139).

HHP is a convenient way to inactivate tumor cells and maintain immunogenicity (49). Fucikova et al reported that HHP treatment with $250 \mathrm{MPa}$ induced ICD in human acute lymphocytic leukemia, prostate, and ovarian cancer cell lines, and primary tumor cells (140). HHP-induced ICD in tumor cells exhibited molecular characteristics similar to 
those induced by anthracyclines (141), such as induction of endoplasmic stress response and ROS formation, cell surface exposure of HSP and calreticulin, and release of ATP and HMGB1 (122). Physical cell death induction modalities, such as HHP or heat treatment (HT), have been demonstrated to be used as vaccines and to help induce antitumor immunity in patients. These modalities, especially HHP treatment, are effective inducers of ICD in malignant cells and may have a great potential in the development of new DC-based or whole cell-based vaccines.

Urbanova et al reported that lung cancer cells treated with 150, 200 and $250 \mathrm{MPa}$ HHP exhibited a distinct ICD-induced temporal pattern, but incubating them with DCs for $24 \mathrm{~h}$ equally stimulated the expression of maturation-related and co-stimulatory molecules (130). When tumor cells were treated with ICDs, they activated various immune cells to stimulate antitumor immune responses (142). These findings demonstrated the significant role of the immune system in the antitumor treatment. Nevertheless, more research is required on the molecular mechanism of HHP and HT-induced ICDs, as well as on the CT drugs and radiation currently used, to optimize the treatment strategies. Future research should strive to incorporate the design of novel modern ICD-inducing agent-based immunotherapies into current multimodal oncology treatment regimens.

\section{High hydrostatic pressure and dendritic cell-based tumor vaccines}

DCs play a key role in the immune response because they can capture antigens bound to the pattern recognition receptors, process and present them to the naive $\mathrm{T}$ cells, thus inducing the T-cell activation and thus creating an important bridge between the innate and adaptive immune systems (143). DCs have been demonstrated to play a crucial role in the induction of antitumor immune responses (119). DC-based immunotherapy is safe and induces antitumor immunity in patients with advanced melanoma (144). De Sanctis et al revealed that in an orthotopic mouse model of prostate cancer, the experimental group demonstrated that DC-based vaccines were as effective as CT in slowing tumor growth (145). Mikyskova et al demonstrated that DC-based vaccines were a reasonable tool for treating human prostate cancer (126). Hradilova et al reported important preclinical data from phase I/II clinical trials in non-small cell lung cancer (NSCLC) using DC-based active cellular immunotherapy in combination with CT and immune boosters for the treatment of NSCLC (127). Urbanova et al also reported important preclinical data from an ongoing phase I/II clinical trial in NSCLC involving the use of DC-based active cellular immunotherapy to produce immunogenically-killed lung cancer cells (130). These studies demonstrated that a DC vaccine can lead to long-lasting tumor immunity, a process that requires three steps (146). In the first step, DCs must obtain the relevant TAAs. Secondly, DCs have to mature and induce T-cell responses. In DC-based cellular immunotherapy, the enhanced ability of DCs to co-stimulate naive $\mathrm{T}$ cells during maturation may be important. The final step is to allow $\mathrm{T}$ cells to overcome the immunosuppression of the primary solid tumor and enter the tumor bed (146).

The success of DC-based tumor immunotherapy depends on the range of TAAs presented by DCs and the ability of
DCs to produce cytokines such as IL-12p70 and provide the co-stimulation to T cells (147). Immature DCs are constantly migrating in the tissues and blood, scanning the environment for danger signals or potential pathogens (148). These pathogens and signals can activate innate immunity and interact with pattern recognition receptors, purinergic receptors, and phagocytosis-related receptors expressed by DCs and stimulate the presentation of tumor antigens to T cells (148). Typically, autologous DC-based vaccines use in vitro cultures of DCs loaded with the tumor antigens and promote the maturation of the DCs (149). Tumor cells are phagocytosed after being recognized by DCs, which then undergo antigenic processing. DCs must reach the mature stage to induce an effective immune response because semi-mature DCs have tolerogenic features (146). The maturation of DCs is accompanied by a decrease in antigen assimilation and an increase in migration capacity. DCs move to the lymph nodes (LN), where the complex of peptide and MHC-class II is presented to the antigen-specific T-cell receptor (TCR) on the naive CD4 ${ }^{+} \mathrm{T}$-cell. This again indicates the enhanced DCs function in tumor patients (150).

Tumor cells can be inactivated by different methods and the choice of the optimal inactivation method is crucial for the DC vaccine optimization (15). HHP treatment has been revealed to maintain immunogenic tumor cell inactivation. HHP-treated tumor cells can induce the monocyte-derived DC maturation. DCs cultured with HHP-treated tumor cells can also induce the activation of T cells in vitro (49). Phagocytosis of HHP-killed tumor cells by DC stimulates the expression of maturation-associated molecules on DCs and induces the production of proinflammatory cytokines. The tendency of increased numbers of the $\mathrm{CD}^{+} \mathrm{T}$ cells and the natural killer (NK) cells in the spleens of the experimental animals are detected when DCs are pulse-stimulated with HHP-treated tumor cells $(126,130)$.

Fucikova et al reported that the interaction of immature DCs with HHP-treated tumor cells resulted in the increased uptake of tumor cells by DCs and induced the expression of maturation-related molecules on DCs and the production of IL-12p70 and the related proinflammatory cytokines, suggesting that HHP-treated tumor cells provided an effective activation stimulus to DCs (140). Human monocyte-derived DCs pulsed with HHP-treated tumor cells, showing increased expression of maturation-related molecules and the production of the pro-inflammatory cytokine, resulting in the stimulation of $\mathrm{CD} 4^{+}$and $\mathrm{CD}^{+} \mathrm{T}$ cells produced by interferon- $\gamma($ IFN- $\gamma$ ) in vitro (140). These results suggested that despite few antigens detected by the western blot test, a significant amount of antigens were still present in DC-processed cells and presented in the major histocompatibility complex (MHC) class I molecules to $\mathrm{CD}^{+} \mathrm{T}$ cells (127). Hradilova et al revealed that a DC-based HHP-treated lung cancer vaccine produced by monocytes from NSCLC patients induced antigen-specific $\mathrm{CD}^{+}$and $\mathrm{CD}^{+} \mathrm{T}$ cells (127). A DC-based vaccine combined with the HHP-treated transgenic adenocarcinoma of the mouse prostate tumor cells combined with docetaxel CT significantly reduced tumor growth in each mouse model (151). These encouraging results revealed that HHP can be a significant method for tumor cell inactivation. 


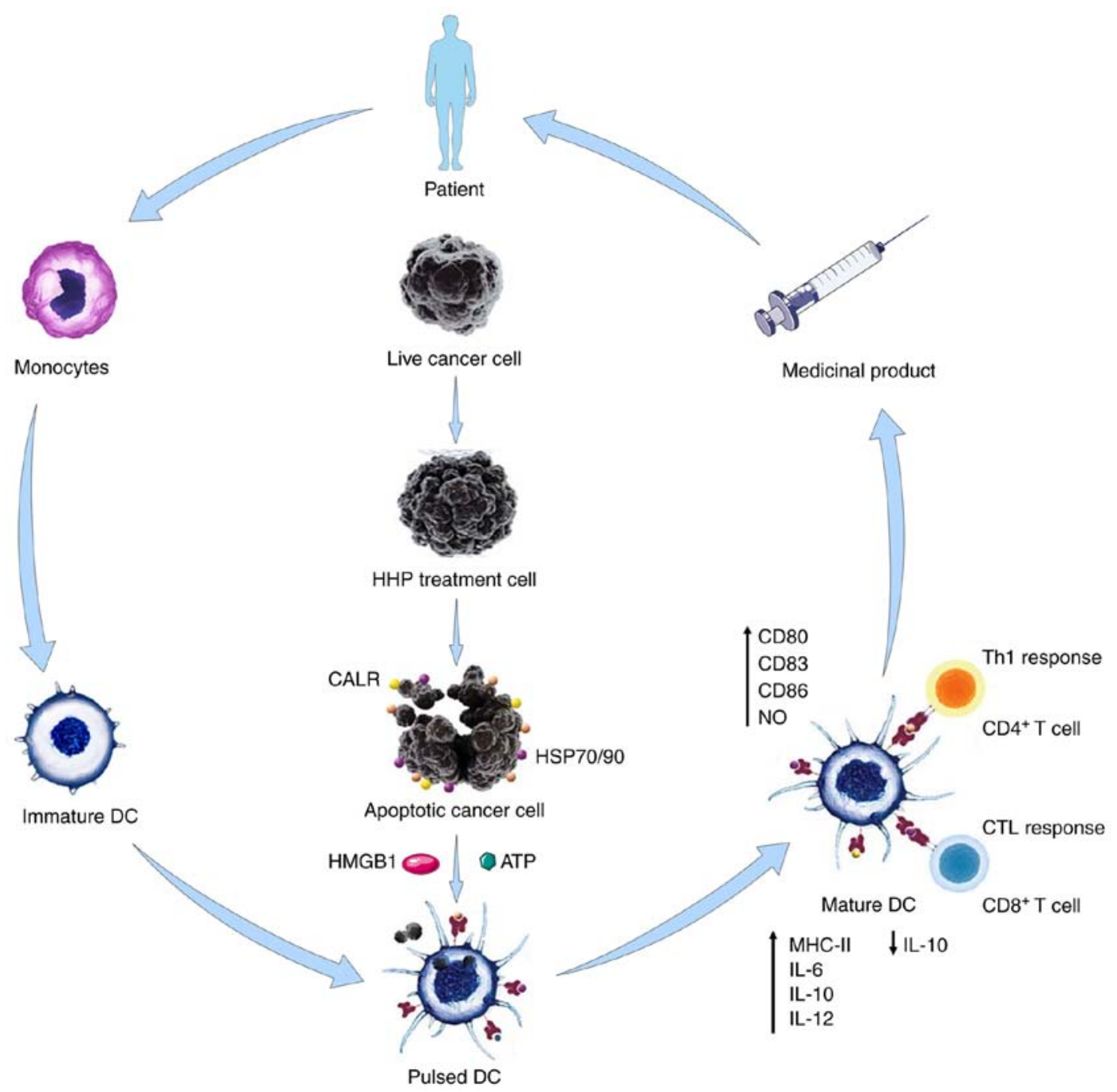

Figure 3. Manufacturing of the DC-based vaccine using immunogenic HHP-treated cancer cells. The live cancer cells are treated with HHP treatment. Then, cancer cells are cultured for a few hours to expose relevant immunogenic molecules on the treated cell surfaces (HSP70/90 and CALR) or released into the vicinity of dying cells (ATP and HMGB1). HHP-treated cancer cells are loaded to DCs, which are made from mononuclear cells obtained from patients. DCs generated from pulses of cancer cells treated with HHP can mature. DCs acquire the stimulatory phenotype with the high expression of costimulatory molecules (CD80, CD83, CD86), MHC class II molecules, and with the production of proinflammatory cytokines (IL-1 1 , IL-6, IL-12) and the mediators such as NO. Anti-inflammatory cytokines such as IL-10 are produced in lower amounts. Some doses of the DC-based vaccines are prepared, cryopreserved, and administered back to the patients in the course of therapy. ATP, adenosine triphosphate; CALR, calreticulin; DC, dendritic cell; HHP, high hydrostatic pressure; HMGB1, high mobility group box 1; HSP, heat shock protein; IL, interleukin; MHC, major histocompatibility complex; NO, nitric oxide.

HHP treatment for tumor cells can be standardized according to GMP requirements and incorporated into manufacturing protocols for DC-based cellular CI (130). More importantly, DCs loaded with HHP-treated tumor cells exhibited enhanced phagocytosis, expressed high levels of co-stimulatory molecules, and stimulated a large number of specific $\mathrm{T}$ lymphocytes, whereas no $\mathrm{T}$ regulatory cells were induced in the absence of the additional immunostimulatory agents (140). Mature DCs express high levels of co-stimulatory molecules and peptide-bound MHC class I and II molecules and produce pro-inflammatory cytokines, which are essential for efficient stimulation of tumor antigen-specific T-cell responses (152). These interactions effectively activate DCs to phagocytose dying tumor cells and allow them to mature and acquire an immunostimulatory phenotype (152). A schematic diagram of DC-based vaccine preparation using immunogenic HHP-treated tumor cells, which can be applied to other physical tumor cell death-inducing modalities is presented in Fig. 3.

\section{Tumor vaccines and Annexin A5}

Phospholipids, such as lysophosphatidylcholine (LPC) and phosphatidylserine (PS), are involved in the clearance of apoptotic and necrotic cells. Apoptotic exposure of PS is one of the main 'eat me' signals for macrophages (153). Annexin A5 (Anx A5), a high specific ligand for PS, is an important modulator of immune responses against the PS-exposed particles (154). AnxA5 is also the focus of therapeutic applications for the delivery of drugs to the relevant cells expressing PS on the cell surface (154). AnxA5 binds to phospholipids in a $\mathrm{Ca}^{2+}$ dependent manner and it blocks the phagocytosis of dying tumor cells by macrophages, but not DCs. Thus, the clearance of dying tumor cells is transferred from macrophages to DCs (155).

PS also expose the luminal surfaces of the vascular endothelium of tumors. In animal models, antibody-targeting of PS damages tumor vasculature and induces antitumor immune 


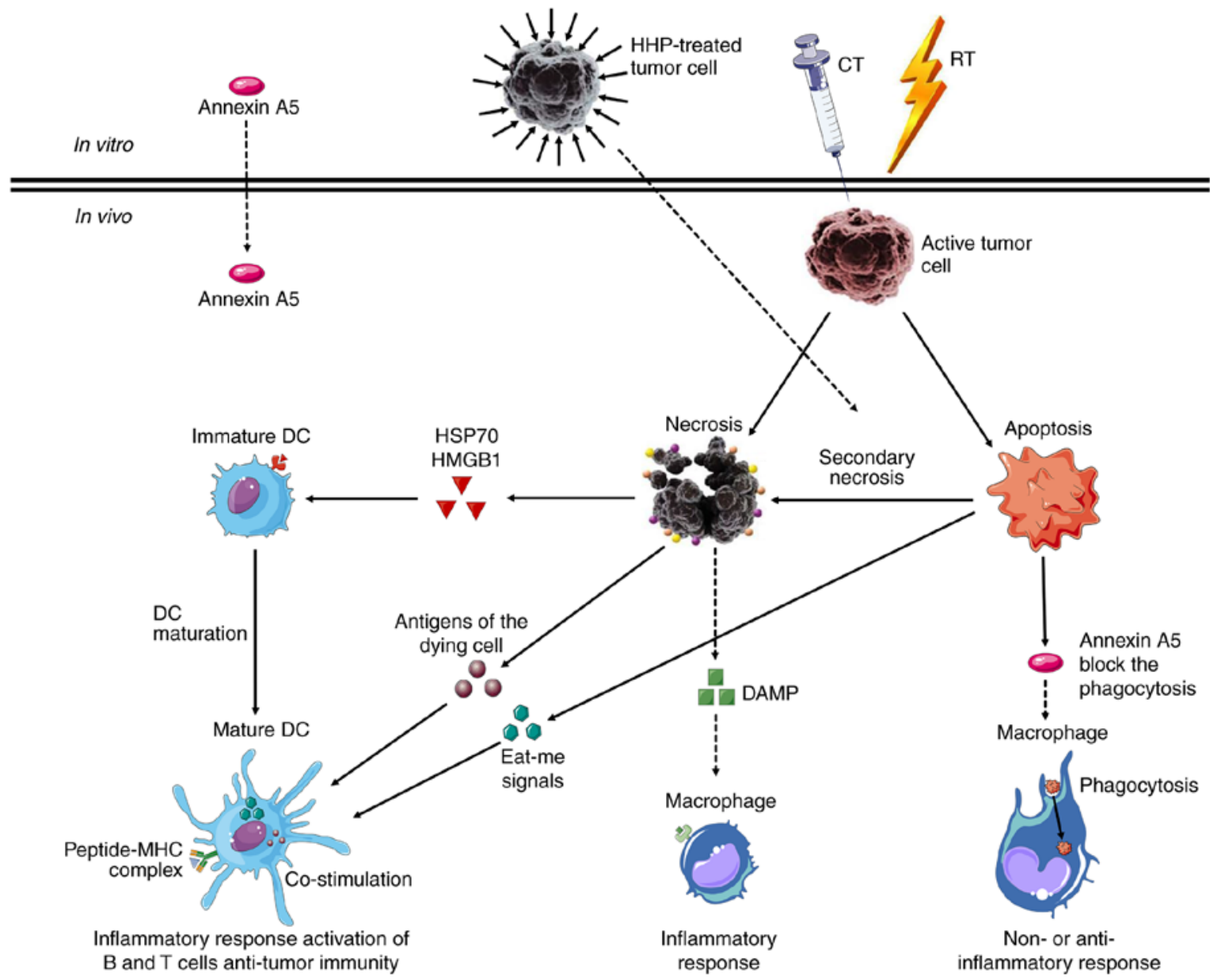

Figure 4. DC-mediated immune responses against cancer induced by dead cancer cells and the adjuvant AnxA5. Apoptotic and necrotic tumor cells resulting from treatment as well as from in vitro inactivation interact with immune cells of the innate (macrophages) and adaptive (DC) immune system. The swift clearance of apoptotic cells leads to anti-inflammatory or non-inflammatory responses. The clearance of apoptotic cancer cells by macrophages can be blocked by AnxA5, resulting in abundant secondary necrosis. The necrotic cells can release DAMPs, such as HMGB1 or HSP70, which are danger signals. Stimulation of danger signals and uptake and presentation of dead cancer cell-derived antigens by DCs leads to the specific antitumor immunity. Danger signals may also directly activate cells of the innate immune system. The 'eat me' signals of early apoptotic cells can promote the phagocytosis of dying cancer cells by DCs. AnxA5, Annexin A5; DAMPs, damage-associated molecular patterns; DC, dendritic cell; HMGB1, high mobility group box 1; HSP70, heat shock protein 70.

responses (156). In addition in vivo, the provided AnxA5 decreased the uptake of apoptotic cells by the peritoneal macrophages and increased their uptake by DCs (157). In summary, Anx A5 promotes DC uptake by interfering with the macrophage-mediated clearance of apoptotic and necrotic tumor cells. In the presence of AnxA5, the microenvironment becomes inflammatory and leads to the regression of allogeneic tumors as well as the rejection and cure of the syngeneic tumors. The influence of AnxA5 on clearance of apoptotic tumor cells and antitumor immunity is presented in Table III.

The pattern of tumor cell death, whether induced by treatments in vivo or by inactivation of tumor cells in vitro for vaccine preparation purposes, has made an important contribution to the efficacy of antitumor immune responses (Fig. 4). The synergy of immunotherapy and RT has the potential to provide better local tumor cell targeting by providing better tumor control in non-irradiated areas (158). Individual differences in response to standard tumor therapies are usually observed clinically, ranging from complete remission to treatment progression. RT, CT, and AnxA5 are all considered as the immune modulators of tumors (159). They change the tumor cell phenotype early after the application. Exposure to stress proteins such as HSP70 and phagocytic recognition molecules such as PS can kill tumor cells through apoptosis or necrosis (160). The latter exists in a programmed and accidental form. Necrotic cells lose membrane integrities, leading to the release of immune-activated DAMPs, such as HMGB1, ATP, or HSP70, while apoptotic cells maintain membrane integrity and DAMPs are hidden (161). Apoptotic cells are cleared and recognized rapidly by PS, and macrophages release anti-inflammatory cytokines, resulting in an immunosuppressive microenvironment (162). Conversely, DAMPs mature and activate DCs, thereby promoting the cross-presentation of tumor cell-derived antigens with $\mathrm{T}$ cells.

In addition, DAMPs may also directly activate cells of the innate immune systems, such as NK cells (163). Inhibition of apoptotic cell clearance by macrophages with AnxA5, or induction of abundant apoptotic cells in a multimodal treatment setting, can promote the necrotic immune form of tumor cells (164). Immunogenic forms of tumor cell death can also be induced by killing biopsy-derived fresh tumor cells in vitro, resulting in complete cell death by increasing the immunogenicity (165). Fig. 5 summarizes the principle of multimodal treatments to induce tumor cell death leading to antitumor immunity. 
Table III. Influence of Annexin A5 on the clearance of the apoptotic tumor cells and on the antitumor immunity.

Treated tumor cells without Annexin A5

Treated tumor cells with Annexin A5

Phagocytosis (macrophages dominated)

High TGF- $\beta$ secretion

Phagocytosis (dendritic cells dominated)

Low response of the xenogeneic $\lg G$

High IL- $1 \beta$ and TNF $\alpha$ secretion

Slow allogeneic tumor regression

High response of the xenogeneic $\lg G$

Induce moderate tumor rejection rates

Fast allogeneic tumor regression

Induce low tumor cure rates

Induce high tumor rejection rates

Induce high tumor cure rates

Table IV. List of experimental studies involving the preparation of tumor cells killed by means of high hydrostatic pressure for use as vaccines in cancer immunotherapy.

\begin{tabular}{lllccc}
\hline Author & Year & \multicolumn{1}{c}{ Cell line } & Pressure (MPa) & Duration & (Refs.) \\
\hline Liu et al & 2020 & B16-F10 & $50-500$ & $1-120 \mathrm{~min}$ & $(48)$ \\
Seitz et al & 2019 & B16-F10 and CT26 & $100-500$ & $300 \mathrm{sec}$ & $(49)$ \\
Mikyskova et al & 2017 & TC-1 and TRAMP-C2 & 200 & $10 \mathrm{~min}$ & $(126)$ \\
Hradilova et al & 2017 & H520, H522, and A549 & 250 & $10 \mathrm{~min}$ & $(127)$ \\
Urbanova et al & 2017 & LNCap, OV-90 and SK-OV-3, and H522 and A549 & $150-350$ & $10-15 \mathrm{~min}$ & $(130)$ \\
Moserova et al & 2016 & OV-90 and CT26 & $150-250$ & $10 \mathrm{~min}$ & $(119)$ \\
Mikyšková et al & 2016 & TC-1 and TRAMP-C2 & $100-200$ & $10 \mathrm{~min}$ & $(151)$ \\
Fucikova et al & 2014 & ALL cell lines, OV-90, and LNCap & $150-250$ & $10 \mathrm{~min}$ & $(140)$ \\
Weiss et al & 2010 & B16-F10, CT26, MCF7 and Raji & $100-500$ & Over 300 sec & $(46)$ \\
\hline
\end{tabular}

ALL, acute lymphoblastic leukemia; B16-F10, melanoma cells; CT26, colon carcinoma cells; H520, H522, and A549, non-small cell lung cancer cell lines; LNCap, Prostate cancer cell line; MCF7, human adenocarcinoma cell line; OV-90 and SK-OV-3, ovarian cancer cell lines; Raji, human Burkitt's lymphoma B-lymphocyte; TC-1, lung tumor cell line; TRAMP-C2, transgenic adenocarcinoma mouse prostate cell; $\mathrm{MPa}$, megapascal.

\section{Conclusions and outlooks}

The purpose of this short review was to summarize the knowledge and applications of HHP technology in the development of tumor vaccines and to envisage new possible research directions and applications. HHP technology has great potential for the development of tumor vaccines and provides a new treatment scheme for cancer patients (Table IV). Achieving the sustained antitumor response is a major limitation of most current therapeutic methods of solid tumors and additional and multimodal treatment approaches are required. HHP technology is an effective method for producing whole-cell vaccines or DC-based antitumor vaccines. However, to date, studies of both vaccines remain in the preclinical phase (41). Therefore, there is still a need to develop new vaccines for treatment with HHP that can avoid the disadvantages of existing HHP vaccines and activate the immune system to produce sustained antitumor immunity (Table V).

Tumor vaccines require activation of $\mathrm{T}$ cells to resist the immunosuppressive microenvironment (166). Progressive tumors usually promote tumor growth by promoting infiltration of tumor-bearing M2-like macrophages, myeloid-derived suppressor cells (MDSC), and regulatory T (T-Reg) cells, thereby inhibiting the local expansion and effector functions of $\mathrm{CD}^{+} \mathrm{T}$ helper cells and cytotoxic $\mathrm{CD} 8^{+} \mathrm{T}$ cells (167).
Reluctant T-cell transfer vaccines with or without costimulatory antibodies, particularly against CD27, CD40, and CD137, can expand the tumor-specific T-cell pool (168). In most patients, $\mathrm{T}$ cell-mediated immunity in the tumor microenvironment is affected by several mechanisms of suppressive immune cell use within the tumor as well as by T-cell checkpoint suppression (169). This converts T cells into lymphocytes, which may have a transient but modest effect on the tumor. Specialized and selective regulation of the microenvironment may lead to temporary tumor shrinkage and render intra-tumor T cells resistant to the tumor (170). This may be achieved by inducing an acute inflammatory response using pattern recognition receptor (PRR) agonists or by removing or inhibiting regulatory mechanisms that modulate immunity [T-Reg cells, MDSC, and/or M2 tumor-associated macrophages (TAM)] (171). If there is no additional activation of a strong tumor-specific T-cell response, there is no significant effect on tumor growth in most patients (172). If a tumor-specific T-cell response has been ignited, checkpoints against cytotoxic T-lymphocyte-associated protein 4, programmed cell death protein 1 , lymphocyte activation gene 3 , antibody to T-cell immunoglobulin mucin receptor 3, or natural killer cell receptor A (or against their respective ligands) can help maintain the full effector function of T cells within the tumor (173). In some patients, this will lead to tumor destruction, while in 
Table V. Advantages and disadvantages of applying HHP technology for cancer immunotherapy.

Advantages of HHP technology

Disadvantages of HHP technology

i) HHP technology as a physical modality leaves no chemical residue in killed cancer cells

ii) Cryopreservation of HHP-treated tumor cells does not affect the immunogenicity

iii) HHP technology-killed tumor cells represent a multi-antigenic vaccine compared to numerous other types of antigen-specific vaccines

iv) More efficient immunogenic cell death induction in tumor cells by HHP technology over other modalities such as DC-based vaccine generation or UV light used in whole cell vaccine i) Optimization magnitude of HHP for effective immunogenic treating of tumor cells and tumor-antigen content

ii) Customized HHP-generating device compliant with GMP requirements for the vaccine generation

iii) Allogeneic cell lines used for the HHP vaccine generation lack on the specific neoantigens of the patients

HHP, high hydrostatic pressure; DC, dendritic cell; UV, ultra-violet; GMP, good manufacturing processes.

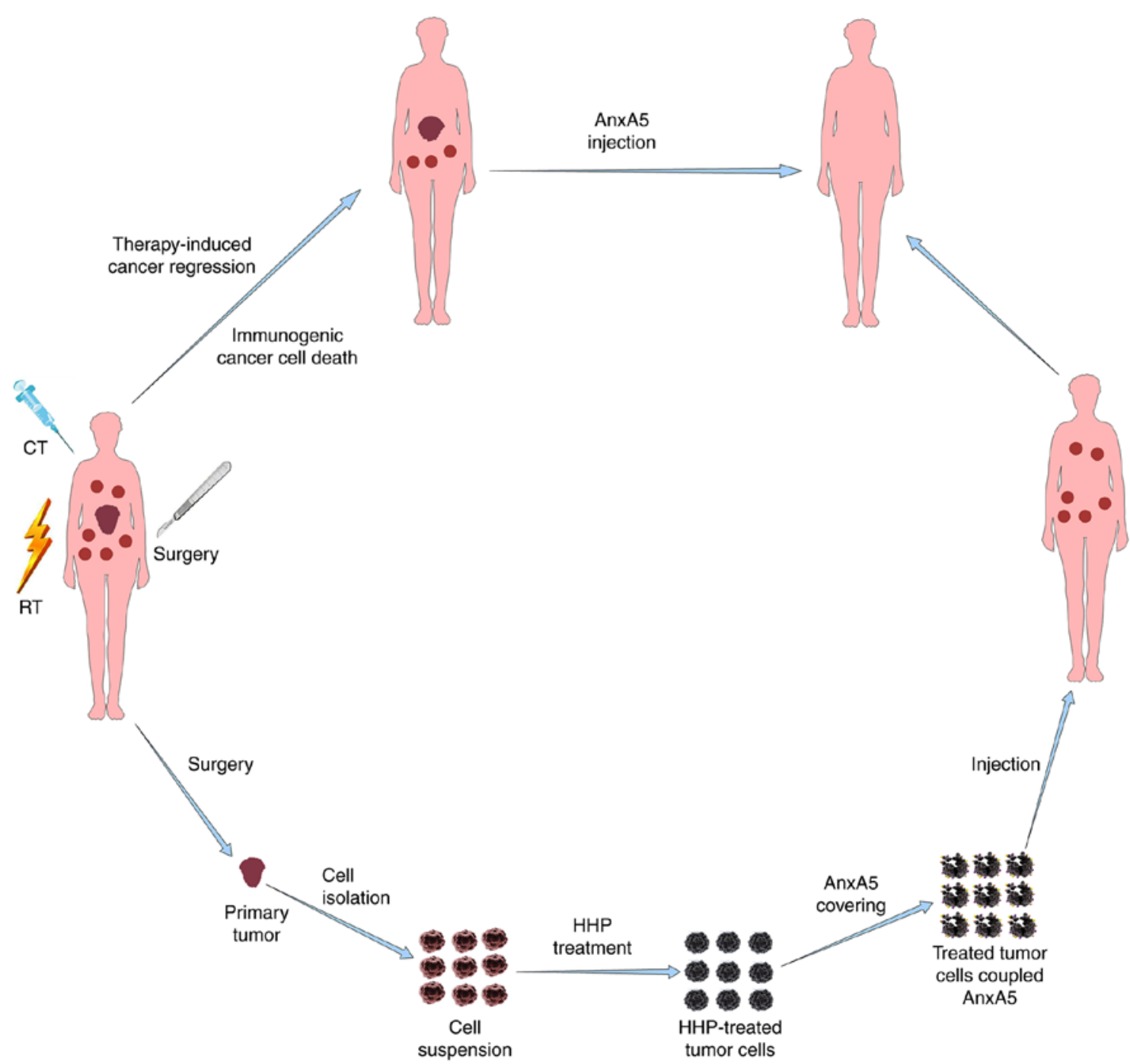

Figure 5. Standard tumor therapy combines with immune therapy and act together in the elimination of tumors. In vivo, therapy-induced cancer cell death by RT and CT can be more immunogenic using the immune-stimulatory adjuvant AnxA5. HHP-treated tumor cells can be incubated with recombinant AnxA5 to further enhance the immunogenicity before reinjection into patients. AnxA5 may also increase the immunogenicity of malignant cells prepared from the primary tumor for vaccination purposes. Complete cancer cell killing by preserving the immunogenicity can be achieved by the inactivation of autologous cancer cells with HHP. The injection of AnxA5 can modulate the anticancer response of dead cancer cells induced by RT and CT treatment. The results reveal that the growth of the syngeneic tumors is not only inhibited by RT but also solely by treatment with AnxA5. AnxA5, Annexin A5; CT, chemotherapy; HHP, high hydrostatic pressure; RT, radiotherapy. 
others, immunosuppression of cells in the microenvironment may prevail (174). In situations where immunosuppression is alleviated and the tumor is sufficiently immunogenic, activation of DCs and M1-like TAMs will promote the attraction and activation of tumor-specific $\mathrm{T}$ cells and maintain the antitumor activity over time (175). They may lead to tumor eradication.

Several studies have observed in groups of patients with different types of tumors that patients have improved outcomes with immunotherapy when B cells compose a cluster of cells called tertiary lymphoid structures (TLS) within the tumor $(176,177)$. Tumor-infiltrating B lymphocytes have been found in some tumor tissues and are an important component of TLS in tumor tissues (178). Tertiary lymphoid structures are ectopic lymphoid organs formed in non-lymphoid tissues during chronic inflammatory as well as tumor formation and consist of T cells, B cells, follicular dendritic cells, as well as other cells (179). TLS can be present in tumor tissue in various states of maturation, with the highest level forming germinal center structures (180). The impact of tumor-infiltrating B cells and TLS on tumor formation and the efficacy of immunotherapy have also received attention (180), but their specific roles in tumors and their underlying mechanisms are not fully understood. These results also indicate new directions for subsequent research, combining $\mathrm{T}$ cell-mediated immunotherapy with approaches using B cells, which may lead to more effective antitumor therapies for more patients.

Inactivation technologies used to prepare tumor cell vaccines should be aimed at inducing immunogenic malignant cell death forms. If tumor cell vaccines are prepared by the inactivation of whole tumor cells, the immunogenicity of the dead tumor cells should be enhanced or at least maintained by this procedure. The main focus of future oncology treatment concepts should be to combine classical antitumor therapy with immunotherapy to achieve the synergistic antitumor effects of both modalities.

\section{Acknowledgements}

Not applicable.

\section{Funding}

This work was supported by the Funds of Jilin Provincial Finance Department (grant no. JLSCZD2019-002).

\section{Availability of data and materials}

The datasets used during the present study are available from the corresponding author upon reasonable request.

\section{Authors' contributions}

KL and BL conceived and designed the study and prepared the manuscript. SY and JL were responsible for the literature search, data visualization, and analysis. LM and WT retrieved the relevant literature and revised the manuscript for important intellectual content. All authors read and approved the final manuscript.

\section{Ethics approval and consent to participate}

Not applicable.

\section{Patient consent for publication}

Not applicable.

\section{Competing interests}

The authors declare that they have no competing interests.

\section{References}

1. Hoover DG and Farka DF: Biological effects of high hydrostatic pressure on food microorganisms. Food Technol 43: 99-107, 1989.

2. Komora N, Maciel C, Pinto CA, Ferreira V, Brandão TRS, Saraiva JMA, Castro SM and Teixeira P: Non-thermal approach to Listeria monocytogenes inactivation in milk: The combined effect of high pressure, pediocin PA-1 and bacteriophage P100. Food Microbiol 86: 103315, 2020.

3. Lin T, O'Keefe S, Duncan S and Fernández-Fraguas C: Manipulation of the dry bean (Phaseolus vulgaris L.) matrix by hydrothermal and high-pressure treatments: Impact on in vitro bile salt-binding ability. Food Chem 310: 125699, 2020.

4. Li X, Xue YM, Guo HM, Deng CY, Peng DW, Yang H, Wei W, Liu Y, Liu FZ, Wang ZY, et al: High hydrostatic pressure induces atrial electrical remodeling through upregulation of inflammatory cytokines. Life Sci 242: 117209, 2020.

5. Kurosaka G, Uemura S, Mochizuki T, Kozaki Y, Hozumi A, Suwa S, Ishii R, Kato Y, Imura S, Ishida N, et al: A novel ER membrane protein Ehg1/May24 plays a critical role in maintaining multiple nutrient permeases in yeast under high-pressure perturbation. Sci Rep 9: 18341, 2019.

6. Guillou S and Membre JM: Inactivation of Listeria monocytogenes, Staphylococcus aureus, and Salmonella enterica under high hydrostatic pressure: A quantitative analysis of existing literature data. J Food Prot 82: 1802-1814, 2019.

7. Romek M, Kucia M, Gajda B, Krzysztofowicz E and Smorag Z: Effect of high hydrostatic pressure on mitochondrial activity, reactive oxygen species level and developmental competence of cultured pig embryos. Theriogenology 140: 99-108, 2019.

8. Azeem M, Mu TH and Zhang M: Effects of high hydrostatic pressure and soaking solution on proximate composition, polyphenols, anthocyanins, $\beta$-carotene, and antioxidant activity of white, orange, and purple fleshed sweet potato flour. Food Sci Technol Int 26: 388-402, 2020.

9. Wang C, Xue Y, Yousaf L, Hu J and Shen Q: Effects of high hydrostatic pressure on the ordered structure including double helices and V-type single helices of rice starch. Int J Biol Macromol 144: 1034-1042, 2020.

10. Bartlett DH: Pressure effects on in vivo microbial processes. Biochim Biophys Acta 1595: 367-381, 2002.

11. Knorr D, Heinz V and Buckow R: High pressure application for food biopolymers. Biochim Biophys Acta 1764: 619-631, 2006.

12. Ott O, Rödel C, Weiss C, Wittlinger M, Krause F, Dunst J, Fietkau R and Sauer R: Radiochemotherapy for bladder cancer. Clin Oncol (R Coll Radiol) 21: 557-565, 2009.

13. Yamashita H, Noguchi S, Murakami N, Toda M, Uchino S, Watanabe $\mathrm{S}$ and Kawamoto $\mathrm{H}$ : Extracapsular invasion of lymph node metastasis. A good indicator of disease recurrence and poor prognosis in patients with thyroid microcarcinoma. Cancer 86 : 842-849, 1999.

14. Pastushenko I and Blanpain C: EMT transition states during tumor progression and metastasis. Trends Cell Biol 29: 212-226, 2019.

15. Vandenberk L, Belmans J, Van Woensel M, Riva M and Van Gool SW: Exploiting the immunogenic potential of cancer cells for improved dendritic cell vaccines. Front Immunol 6: 663, 2016.

16. Markovsky E, Budhu S, Samstein RM, Li H, Russell J, Zhang Z, Drill E, Bodden C, Chen Q, Powell SN, et al: An antitumor immune response is evoked by partial-volume single-dose radiation in 2 murine models. Int $\mathbf{J}$ Radiat Oncol Biol Phys 103: 697-708, 2019.

17. Huang Y, Wang FM, Wang T, Wang YJ, Zhu ZY, Gao YT and Du Z: Tumor-infiltrating FoxP3 ${ }^{+}$Tregs and $\mathrm{CD}^{+} \mathrm{T}$ cells affect the prognosis of hepatocellular carcinoma patients. Digestion 86: 329-337, 2012. 
18. Helmstein K: Treatment of bladder carcinoma by a hydrostatic pressure technique. Report on 43 cases. Br J Urol 44: 434-450, 1972.

19. Goldman Y, Peled A and Shinitzky M: Effective elimination of lung metastases induced by tumor cells treated with hydrostatic pressure and N-acetyl-L-cysteine. Cancer Res 60: 350-358, 2000.

20. Shinitzky M and Goldman Y: Immunotherapy of cancer with pressure modified cells. Isr Med Assoc J 2: 615-620, 2000.

21. Rivalain N, Roquain J and Demazeau G: Development of high hydrostatic pressure in biosciences: Pressure effect on biological structures and potential applications in biotechnologies. Biotechnol Adv 28: 659-672, 2010.

22. Bridgman PW, editor. The measurement of high hydrostatic pressure. I. A simple primary gauge. Proc Am Acad Arts Sci 44, 201-217, 1909.

23. Aertsen A, Meersman F, Hendrickx ME, Vogel RF and Michiels CW: Biotechnology under high pressure: Applications and implications. Trends Biotechnol 27: 434-441, 2009.

24. Frey B, Janko C, Ebel N, Meister S, Schlucker E, Meyer-Pittroff R, Fietkau R, Herrmann M and Gaipl US: Cells under pressure-treatment of eukaryotic cells with high hydrostatic pressure, from physiologic aspects to pressure induced cell death. Curr Med Chem 15: 2329-2336, 2008.

25. Roger H: Action des hautes pressions sur quelques bactéries Arch Physiol Norm Path 7: 12-17, 1895.

26. Hite BH: The effect of pressure in the preservation of milk: A preliminary report. West Virginia Agricultural Experiment Station, 1899.

27. Hite BH, Weakley CE and Giddings NJ: The effect of pressure on certain micro-organisms encountered in the preservation of fruits and vegetables. West Virginia University Agricultural Experiment Station, 1914.

28. Basset J and Macheboeuf MA: Etude sur les effets biologiques des ultrapressions: Résistance des bactéries, des diastases et des toxines aux pressions très élevées. Comp Rend Acad Sci 195: 1431-1433, 1932.

29. Atanasiu P, Barbu E and Basset J: Effect of very high pressure on Newcastle virus. I. Dissociation of infectious power and of hemagglutination. Ann Inst Pasteur (Paris) 81: 340-343, 1951 (In Undetermined Language).

30. Basset J, Lepine P and Chaumont L: Effects of high pressures on the poliomyelitis virus (Lansing strain). Ann Inst Pasteur (Paris) 90: 575-593, 1956 (In French).

31. Basset J, Macheboeuf M and Sandor G: Etudes sur les effets biologiques des ultra-pressions. Action des pressions très élevées sur les protéides. CR Hebd Acad Sci 197: 796-798, 1933.

32. Basset J, Wollman E, Macheboeuf MA and Bardach M: Etudes sur les effets biologiques des ultra-pressions: action des pressions élevées sur les tumeurs. CR Hebd Acad Sci 200: 200, 1935.

33. Johnson FH, Brown D and Marsland D: A basic mechanism in the biological effects of temperature, pressure and narcotics. Science 95: 200-203, 1942.

34. Marsland D and Jaffee O: Effects of pressure on the cleaving eggs of the frog (Rana pipiens). J Cell Comp Physiol 34: 439-450, 1949.

35. Wolpert L, Marsland D and Hirshfield M: The effect of high hydrostatic pressure on the mechanical properties of the surface of the sea-urchin egg. J Cell Sci 8: 87-92, 1971

36. Bourns B, Franklin S, Cassimeris L and Salmon ED: High hydrostatic pressure effects in vivo: Changes in cell morphology, microtubule assembly, and actin organization. Cell Motil Cytoskeleton 10: 380-390, 1988 .

37. Haskin CL, Athanasiou KA, Klebe R and Cameron IL: A heat-shock-like response with cytoskeletal disruption occurs following hydrostatic pressure in MG-63 osteosarcoma cells. Biochem Cell Biol 71: 361-371, 1993.

38. Parkkinen JJ, Ikonen J, Lammi MJ, Laakkonen J, Tammi M and Helminen HJ: Effects of cyclic hydrostatic pressure on proteoglycan synthesis in cultured chondrocytes and articular cartilage explants. Arch Biochem Biophys 300: 458-465, 1993.

39. Chawla R, Patil GR and Singh AK: High hydrostatic pressure technology in dairy processing: A review. J Food Sci Technol 48: 260-268, 2011

40. Huang HW, Hsu CP and Wang CY: Healthy expectations of high hydrostatic pressure treatment in food processing industry. J Food Drug Anal 28: 1-13, 2020.

41. Adkins I, Hradilova N, Palata O, Sadilkova L, Palova-Jelinkova L and Spisek R: High hydrostatic pressure in cancer immunotherapy and biomedicine. Biotechnol Adv 36: 577-582, 2018.
42. Korn A, Frey B, Sheriff A, Gaipl US, Franz S, Meyer-Pittroff R, Bluemelhuberh $G$ and Herrmann M: High hydrostatic pressure inactivated human tumour cells preserve their immunogenicity. Cell Mol Biol (Noisy-le-grand) 50: 469-477, 2004.

43. Patterson MF: Microbiology of pressure-treated foods. J Appl Microbiol 98: 1400-1409, 2005.

44. Jacobo-Velázquez DA and Hernández-Brenes C: Biochemical changes during the storage of high hydrostatic pressure processed avocado paste. J Food Sci 75: S264-S270, 2010.

45. Frey B, Franz S, Sheriff A, Korn A, Bluemelhuber G, Gaipl US, Voll RE, Meyer-Pittroff R and Herrmann M: Hydrostatic pressure induced death of mammalian cells engages pathways related to apoptosis or necrosis. Cell Mol Biol (Noisy-le-grand) 50: 459-467, 2004

46. Weiss EM, Meister S, Janko C, Ebel N, Schlücker E, Meyer-Pittroff R, Fietkau R, Herrmann M, Gaipl US and Frey B: High hydrostatic pressure treatment generates inactivated mammalian tumor cells with immunogeneic features. J Immunotoxicol 7: 194-204, 2010

47. Yamaguchi T, Hashiguchi K, Katsuki S, Iwamoto W, Tsuruhara S and Terada S: Activation of the intrinsic and extrinsic pathways in high pressure-induced apoptosis of murine erythroleukemia cells. Cell Mol Biol Lett 13: 49-57, 2008.

48. Liu K, Yan S, Ma Z and Liu B: Effective pressure and treatment duration of high hydrostatic pressure to prepare melanoma vaccines. Oncol Lett 20: 1135-1142, 2020.

49. Seitz C, Rückert M, Deloch L, Weiss EM, Utz S, Izydor M, Ebel N, Schlücker E, Fietkau R, Gaipl US and Frey B: Tumor Cell-Based vaccine generated with high hydrostatic pressure synergizes with radiotherapy by generating a favorable anti-tumor immune microenvironment. Front Oncol 9: 805, 2019.

50. Nakamura-López Y, Sarmiento-Silva RE, Moran-Andrade J and Gómez-García B: Staurosporine-induced apoptosis in P388D1 macrophages involves both extrinsic and intrinsic pathways. Cell Biol Int 33: 1026-1031, 2009.

51. Ravichandran KS and Lorenz U: Engulfment of apoptotic cells: Signals for a good meal. Nat Rev Immunol 7: 964-974, 2007.

52. Voll RE, Herrmann M, Roth EA, Stach C, Kalden JR and Girkontaite I: Immunosuppressive effects of apoptotic cells. Nature 390: 350-351, 1997.

53. Locher C, Conforti R, Aymeric L, Ma Y, Yamazaki T, Rusakiewicz S, Tesnière A, Ghiringhelli F, Apetoh L, Morel Y, et al: Desirable cell death during anticancer chemotherapy. Ann NY Acad Sci 1209: 99-108, 2010.

54. Fraccaroli L, Alfieri J, Larocca L, Calafat M, Mor G, Leirós CP and Ramhorst R: A potential tolerogenic immune mechanism in a trophoblast cell line through the activation of chemokine-induced $\mathrm{T}$ cell death and regulatory $\mathrm{T}$ cell modulation. Hum Reprod 24: 166-175, 2009.

55. Griffith TS and Ferguson TA: Cell death in the maintenance and abrogation of tolerance: The five Ws of dying cells. Immunity 35 : 456-466, 2011

56. Golstein P and Kroemer G: Cell death by necrosis: Towards a molecular definition. Trends Biochem Sci 32: 37-43, 2007.

57. Lavric M, Miranda-Garcia MA, Holzinger D, Foell D and Wittkowski H: Alarmins firing arthritis: Helpful diagnostic tools and promising therapeutic targets. Joint Bone Spine 84: 401-410, 2017.

58. Rahmani M, Reese E, Dai Y, Bauer C, Kramer LB, Huang M, Jove R, Dent P and Grant $S$ : Cotreatment with suberanoylanilide hydroxamic acid and 17-allylamino 17-demethoxygeldanamycin synergistically induces apoptosis in $\mathrm{Bcr}_{-} \mathrm{Abl}^{+} \psi$ ells sensitive and resistant to STI571 (imatinib mesylate) in association with down-regulation of Bcr-Abl, abrogation of signal transducer and activator of transcription 5 activity, and Bax conformational change. Mol Pharmacol 67: 1166-1176, 2005.

59. Shin SA, Moon SY, Park D, Park JB and Lee CS: Apoptotic cell clearance in the tumor microenvironment: A potential cancer therapeutic target. Arch Pharm Res 42: 658-671, 2019.

60. Paudel YN, Angelopoulou E, Piperi C, Balasubramaniam VRMT, Othman I and Shaikh MF: Enlightening the role of high mobility group box 1 (HMGB1) in inflammation: Updates on receptor signalling. Eur J Pharmacol 858: 172487, 2019.

61. Kepp O, Tesniere A, Schlemmer F, Michaud M, Senovilla L, Zitvogel L and Kroemer G: Immunogenic cell death modalities and their impact on cancer treatment. Apoptosis 14: 364-375, 2009.

62. Munoz LE, Frey B, Pausch F, Baum W, Mueller RB, Brachvogel B, Poschl E, Rodel F, von der Mark K. Herrmann M and Gaipl US: The role of Annexin A5 in the modulation of the immune response against dying and dead cells. Curr Med Chem 14: 271-277, 2007. 
63. Sachet M, Liang YY and Oehler R: The immune response to secondary necrotic cells. Apoptosis 22: 1189-1204, 2017.

64. Gross M and Jaenicke R: Proteins under pressure. The influence of high hydrostatic pressure on structure, function and assembly of proteins and protein complexes. Eur J Biochem 221: 617-630, 1994.

65. Avagyan S, Vasilchuk D and Makhatadze GI: Protein adaptation to high hydrostatic pressure: Computational analysis of the structural proteome. Proteins 88: 584-592, 2020.

66. Matsuki H, Kato K, Okamoto H, Yoshida S, Goto M, Tamai N and Kaneshina S: Ligand partitioning into lipid bilayer membranes under high pressure: Implication of variation in phase-transition temperatures. Chem Phys Lipids 209: 9-18, 2017.

67. Perreault V, Hénaux L, Bazinet L and Doyen A: Pretreatment of flaxseed protein isolate by high hydrostatic pressure: Impacts on protein structure, enzymatic hydrolysis and final hydrolysate antioxidant capacities. Food Chem 221: 1805-1812, 2017.

68. Ding W, Palaiokostas M, Shahane G, Wang W and Orsi M: Effects of high pressure on phospholipid bilayers. J Phys Chem B 121: 9597-9606, 2017.

69. Guo K, Xiao W and Qiu D: Polymerization of actin filaments coupled with adenosine triphosphate hydrolysis: Brownian dynamics and theoretical analysis. J Chem Phys 135: 105101, 2011.

70. Harrison SL, Barbosa-Cánovas GV and Swanson BG: Pulsed electric field and high hydrostatic pressure induced leakage of cellular material from saccharomyces cerevisiae. Pulsed Electric Fields in Food Processing, Fundamental Aspects and Applications, pp183-191, 2019.

71. Bridgman PW: The coagulation of albumen by pressure. J Biol Chem 19: 511-512, 1914.

72. Grant EA, Dow RB and Franks WR: Denaturation of egg albumin by pressure. Science 94: 616, 1941.

73. Franck M, Perreault V, Suwal S, Marciniak A, Bazinet L and Doyen A: High hydrostatic pressure-assisted enzymatic hydrolysis improved protein digestion of flaxseed protein isolate and generation of peptides with antioxidant activity. Food Res Int 115: 467-473, 2019.

74. Charlier C, Alderson TR, Courtney JM, Ying J, Anfinrud P and Bax A: Study of protein folding under native conditions by rapidly switching the hydrostatic pressure inside an NMR sample cell. Proc Natl Acad Sci USA 115: E4169-E4178, 2018.

75. Barba FJ, Poojary MM, Wang J, Olsen K and Orlien V: Effect of high pressure processing and storage on the free amino acids in seedlings of Brussels sprouts. Innov Food Sci Emerg Technol 41: 188-192, 2017.

76. Gederaas OA, Rasch MH, Berg K, Lagerberg JW and Dubbelman TM: Photodynamically induced effects in colon carcinoma cells (WiDr) by endogenous photosensitizers generated by incubation with 5 -aminolaevulinic acid. J Photochem Photobiol B 49: 162-170, 1999.

77. Kobayashi M, Ohata K and Yoshida A (eds): Mitochondria membrane potential and developmental ability of mouse oocytes were enhanced by high hydrostatic pressure treatment. Human Reproduction, Oxford Univ Press Great Clarendon St, Oxford Ox2 6dp, 2017.

78. Shuai C, Liu G, Yang Y, Yang W, He C, Wang G, Liu Z, Qi F and Peng S: Functionalized $\mathrm{BaTiO}_{3}$ enhances piezoelectric effect towards cell response of bone scaffold. Colloids Surf B Biointerfaces 185: 110587, 2020.

79. Ribeiro S, Puckert C, Ribeiro C, Gomes AC, Higgins MJ and Lanceros-Méndez S: Surface charge-mediated cell-surface interaction on piezoelectric materials. ACS Appl Mater Interfaces 12: 191-199, 2020

80. Tölgyesi FG and Böde C: Pressure and heat shock proteins Comparative High Pressure Biology, CRC Press, pp57-74, 2016.

81. Nguyen HTM, Akanuma G, Hoa TTM, Nakai Y, Kimura K, Yamamoto $\mathrm{K}$ and Inaoka $\mathrm{T}$ : Ribosome reconstruction during Recovery from High-Hydrostatic-Pressure-Induced injury in Bacillus subtilis. Appl Environ Microbiol 86: e01640-19, 2019.

82. Mota MJ,Lopes RP, Delgadillo I and Saraiva JA: Microorganisms under high pressure-adaptation, growth and biotechnological potential. Biotechnol Adv 31: 1426-1434, 2013.

83. Al-Ayoubi SR, Schinkel PKF, Berghaus M, Herzog M and Winter R: Combined effects of osmotic and hydrostatic pressure on multilamellar lipid membranes in the presence of PEG and trehalose. Soft matter 14: 8792-8802, 2018.

84. Mato JM: Lipid components of cellular membranes. Phospholipid Metabolism in Cellular Signaling, CRC Press, pp1-8, 2018.
85. Nickels JD, Chatterjee S, Stanley CB, Qian S, Cheng X, Myles DA, Standaert RF, Elkins JG and Katsaras J: The in vivo structure of biological membranes and evidence for lipid domains. PLoS Biol 15: e2002214, 2017.

86. Manisegaran M, Bornemann S, Kiesel I and Winter R: Effects of the deep-sea osmolyte TMAO on the temperature and pressure dependent structure and phase behavior of lipid membranes. Phys Chem Chem Phys 21: 18533-18540, 2019.

87. Winter R and Jeworrek C: Effect of pressure on membranes. Soft Matter 5: 3157-3173, 2009.

88. Valentine RC and Valentine DL: Omega-3 fatty acids in cellula membranes: A unified concept. Prog Lipid Res 43: 383-402, 2004

89. Ritz M, Tholozan JL, Federighi M and Pilet MF: Morphological and physiological characterization of Listeria monocytogenes subjected to high hydrostatic pressure. Appl Environ Microbiol 67: 2240-2247, 2001.

90. Mahara A, Morimoto N, Sakuma T, Fujisato T and Yamaoka T: Complete cell killing by applying high hydrostatic pressure for acellular vascular graft preparation. Biomed Res Int 2014 379607, 2014.

91. Gibson OR, Taylor L, Watt PW and Maxwell NS: Crossadaptation: Heat and cold adaptation to improve physiological and cellular responses to hypoxia. Sports Med 47: 1751-1768, 2017.

92. Sinensky M: Homeoviscous adaptation-a homeostatic process that regulates the viscosity of membrane lipids in Escherichia coli. Proc Natl Acad Sci USA 71: 522-525, 1974

93. Montagne K, Uchiyama H, Furukawa KS and Ushida T: Hydrostatic pressure decreases membrane fluidity and lipid desaturase expression in chondrocyte progenitor cells. J Biomech 47 354-359, 2014

94.Purushothaman S, Cicuta P, Ces O and Brooks NJ: Influence of high pressure on the bending rigidity of model membranes. J Phys Chem B 119: 9805-9810, 2015.

95. Kimura K, Morimatsu K, Inaoka T and Yamamoto K: Injury and recovery of Escherichia coli ATCC25922 cells treated by high hydrostatic pressure at 400-600 MPa. J Biosci Bioeng 123 698-706, 2017

96. Macgregor RB: The interactions of nucleic acids at elevated hydrostatic pressure. Biochim Biophys Acta 1595: 266-276, 2002.

97. Girard E, Prange T, Dhaussy AC, Migianu-Griffoni E, Lecouvey M, Chervin JC, Mezouar M, Kahn R and Fourme R Adaptation of the base-paired double-helix molecular architecture to extreme pressure. Nucleic Acids Res 35: 4800-4808, 2007.

98. Lin X, Long L, Shan X, Zhang S, Shen S and Liu B: In planta mobilization of $\mathrm{mPing}$ and its putative autonomous element Pong in rice by hydrostatic pressurization. J Exp Bot 57: 2313-2323, 2006.

99. Long L, Lin X, Zhai J, Kou H, Yang W and Liu B: Heritable alteration in DNA methylation pattern occurred specifically at mobile elements in rice plants following hydrostatic pressurization. Biochem Biophys Res Commun 340: 369-376, 2006.

100. Aertsen A and Michiels CW: Mrr instigates the SOS response after high pressure stress in Escherichia coli. Mol Microbiol 58 $1381-1391,2005$

101. Kroemer G, Galluzzi L, Vandenabeele P, Abrams J, Alnemri ES Baehrecke EH, Blagosklonny MV, El-Deiry WS, Golstein P, Green DR, et al: Classification of cell death: Recommendations of the nomenclature committee on cell death 2009. Cell Death Differ 16: 3-11, 2009.

102. Abe F: Exploration of the effects of high hydrostatic pressure on microbial growth, physiology and survival: Perspectives from piezophysiology. Biosci Biotechnol Biochem 71: 2347-2357, 2007.

103. Shi G, Yang Q, Zhang Y, Jiang Q, Lin Y, Yang S, Wang H, Cheng L, Zhang X, Li Y, et al: Modulating the tumor microenvironment via oncolytic viruses and CSF-1R inhibition synergistically enhances Anti-PD-1 immunotherapy. Mol Ther 27: 244-260, 2019.

104. Hollingsworth RE and Jansen K: Turning the corner on therapeutic cancer vaccines. NPJ Vaccines 4: 7, 2019.

105. Saldanha G, Flatman K, Teo KW and Bamford M: A novel numerical scoring system for melanoma tumour infiltrating lymphocytes has better prognostic value than standard scoring. Am J Surg Pathol 41: 906-914, 2017.

106. Vano YA, Petitprez F, Giraldo NA, Fridman WH and Sautes-Fridman C: Immune-based identification of cancer patients at high risk of progression. Curr Opin Immunol 51: 97-102, 2018.

107. Qiao Y, Choi JE, Vo JN, Tien JC, Wang L, Xiao L, Simko SA, Delekta AD, Hodge NB, Desai P, et al: Therapeutic targeting autophagy to sensitize cancer immunotherapy in various cancer types. Cancer Res 79 (Suppl 13): S4153, 2019. 
108. Sahin U and Türeci Ö: Personalized vaccines for cancer immunotherapy. Science 359: 1355-1360, 2018.

109. Hanna MG Jr: Autologous tumor vaccines and methods. Google Patents, 2018

110. Buckanovich RJ, Coukos G and Facciabene A: Methods and compositions for treating solid tumors and enhancing tumor vaccines. Google Patents, 2019.

111. Weiss EM, Wunderlich R, Ebel N, Rubner Y, Schlücker E, Meyer-Pittroff R, Ott OJ, Fietkau R, Gaipl US and Frey B Selected anti-tumor vaccines merit a place in multimodal tumor therapies. Front Oncol 2: 132, 2012.

112. Galluzzi L, Buqué A, Kepp O, Zitvogel L and Kroemer G: Immunogenic cell death in cancer and infectious disease. Nat Rev Immunol 17: 97-111, 2017.

113. Basset J, Lépine P and Chaumont L (eds): Effets des hautes pressions sur le virus de la poliomyelite (souche-lansing). Annales de 1 institut pasteur. Paris, 1956.

114. Deckmann M, Haimovitz R and Shinitzky M: Selective release of integral proteins from human erythrocyte membranes by hydrostatic pressure. Biochim Biophys Acta 821: 334-340, 1985

115. Eisenthal A, Gonenne A, Skornick Y, Gelfand A, Kaver I, Yelin A, Yehoshua H, Lifschitz-Mercer B and Shinitzky M: Th2 to Th1 cytokine shift in autologous peripheral blood mononuclear cells responding to autologous human tumor cells modified by hydrostatic pressure and cross-linking (PCL) in vitro. In: Annual Meeting of the American Association of Cancer Research. Heidelberg SB (ed). Vol 37. Springer, Washington, DC, ppA3232, 1996.

116. Chene L, Sader CD, Magalhaes J, Strozzi F, Tibaldi L, Mendez C, Baeriswyl S, Laveissiere A and Bonny C: Microbiome derived peptides stimulate strong immune response against tumor associated antigens and trigger in vivo tumor regression after vaccination. Cancer Res 79 (Suppl 13): S1475, 2019.

117. Weir G, Quinton T, Hutchins JT, Freimark BD and Stanford M Phosphatidylserine-targeting antibodies enhance anti-tumo activity of a tumor vaccine in a HPV-induced tumor model. Cancer Res 77 (Suppl 13): S3657, 2017

118. Xu L, Kwak M, Zhang W, Zeng L, Lee PC and Jin JO: Rehmannia glutinosa polysaccharide induces toll-like receptor 4 dependent spleen dendritic cell maturation and anti-cancer immunity. Oncoimmunology 6: e1325981, 2017.

119. Moserova I, Truxova I, Garg AD, Tomala J, Agostinis P Cartron PF, Vosahlikova S, Kovar M, Spisek R and Fucikova J: Caspase-2 and oxidative stress underlie the immunogenic potential of high hydrostatic pressure-induced cancer cell death Oncoimmunology 6: e1258505, 2016.

120. Kroemer G, Galluzzi L, Kepp O and Zitvogel L: Immunogenic cell death in cancer therapy. Annu Rev Immunol 31: 51-72, 2013.

121. Lin CF, Chen CL, Chang WT, Jan MS, Hsu LJ, Wu RH, Tang MJ, Chang WC and Lin YS: Sequential caspase-2 and caspase-8 activation upstream of mitochondria during ceramideand etoposide-induced apoptosis. J Biol Chem 279: 40755-40761, 2004.

122. Garg AD, Krysko DV, Verfaillie T, Kaczmarek A, Ferreira GB, Marysael T, Rubio N, Firczuk M, Mathieu C, Roebroek AJ, et al: A novel pathway combining calreticulin exposure and ATP secretion in immunogenic cancer cell death. EMBO J 31: 1062-1079, 2012.

123. Sandow JJ, Dorstyn L, O'reilly LA, Tailler M, Kumar S, Strasser A and Ekert PG: ER stress does not cause upregulation and activation of caspase-2 to initiate apoptosis. Cell Death Differ 21: 475-480, 2014

124. Azevedo AP, Silva SN, Reichert A, Lima F, Júnior E and Rueff J: The role of caspase genes polymorphisms in genetic susceptibility to philadelphia-negative myeloproliferative neoplasms in a Portuguese population. Pathol Oncol Res 25: 961-969, 2019

125. Zappasodi R, de Braud F and Di Nicola M: Lymphoma immunotherapy: Current status. Front Immunol 6: 448, 2015.

126. Mikyskova R, Indrova M, Stepanek I, Kanchev I, Bieblova J, Vosahlikova S, Moserova I, Truxova I, Fucikova J, Bartunkova J, et al: Dendritic cells pulsed with tumor cells killed by high hydrostatic pressure inhibit prostate tumor growth in TRAMP mice. Oncoimmunology 6: e1362528, 2017.

127. Hradilova N, Sadilkova L, Palata O, Mysikova D, Mrazkova H, Lischke R, Spisek R and Adkins I: Generation of dendritic cell-based vaccine using high hydrostatic pressure for non-smal cell lung cancer immunotherapy. PLoS One 12, e0171539, 2017.

128. Sakamoto M, Morimoto N, Jinno C, Mahara A, Ogino S, Suzuki S, Kusumoto K and Yamaoka T: Melanin pigments in the melanocytic nevus regress spontaneously after inactivation by high hydrostatic pressure. PLoS One 12: e0186958, 2017.
129. Liang ZL, Mao QY, Wang YP, Zhu FC, Li JX, Yao X, Gao F, Wu X, Xu M and Wang JZ: Progress on the research and development of inactivated EV71 whole-virus vaccines. Hum Vaccin Immunother 9: 1701-1705, 2013

130. Urbanova L, Hradilova N, Moserova I, Vosahlikova S, Sadilkova L, Hensler M, Spisek R and Adkins I: High hydrostatic pressure affects antigenic pool in tumor cells: Implication for dendritic cell-based cancer immunotherapy. Immunol Lett 187: 27-34, 2017.

131. Kammer GM, Kurrasch R and Scillian JJ: Capping of the surface OKT3 binding molecule prevents the T-cell proliferative response to antigens: Evidence that this molecule conveys the activation signal. Cell Immunol 87: 284-294, 1984.

132. Kast WM, Levitsky H and Marincola FM: Synopsis of the 6th Walker's cay colloquium on cancer vaccines and immunotherapy. J Transl Med 2: 20, 2004.

133. Rosenblatt J and Avigan D: Cellular immunotherapy for multiple myeloma. Best Pract Res Clin Haematol 21: 559-577, 2008.

134. Jocham D, Richter A, Hoffmann L, Iwig K, Fahlenkamp D, Zakrzewski G, Schmitt E, Dannenberg T, Lehmacher W, von Wietersheim $\mathbf{J}$ and Doehn C: Adjuvant autologous renal tumour cell vaccine and risk of tumour progression in patients with renal-cell carcinoma after radical nephrectomy: Phase III, randomised controlled trial. Lancet 363: 594-599, 2004.

135. Pfeffer CM and Singh ATK: Apoptosis: A target for anticancer therapy. Int J Mol Sci 19: 448, 2018.

136. Garg AD, Galluzzi L, Apetoh L, Baert T, Birge RB, Bravo-San Pedro JM, Breckpot K, Brough D, Chaurio R, Cirone M, et al: Molecular and translational classifications of DAMPs in immunogenic cell death. Front Immunol 6: 588, 2015.

137. Gomes-da-Silva LC, Zhao L, Arnaut LG, Kroemer G and Kepp O: Redaporfin induces immunogenic cell death by selective destruction of the endoplasmic reticulum and the Golgi apparatus. Oncotarget 9: 31169, 2018.

138. McDaniel A, Anand S, Alzubier A, Berlin J, Hartman H, Uecker D and Nuccitelli R (eds): Profiling the immunogenic cell death (ICD) mechanisms induced by Nano-Pulse Stimulation (NPS) treatment in mouse B16-F10 melanoma tumors using NanoString technology. Pulse Biosciences London, 2017.

139. Wang Q, Ju X, Wang J, Fan Y, Ren M and Zhang H: Immunogenic cell death in anticancer chemotherapy and its impact on clinical studies. Cancer Lett 438: 17-23, 2018.

140. Fucikova J, Moserova I, Truxova I, Hermanova I, Vancurova I, Partlova S, Fialova A, Sojka L, Cartron PF, Houska M, et al: High hydrostatic pressure induces immunogenic cell death in human tumor cells. Int J Cancer 135: 1165-1177, 2014.

141. Fucikova J, Koci L, Pokorna K, Truxova I, Moserova I, Rozkova D and Spisek R: Cryopreservation of apoptotic cancer cells for use in immunotherapy against cancer. Google Patents, 2019.

142. Iribarren K, Buque A, Mondragon L, Xie W, Lévesque S, Pol J, Zitvogel L, Kepp O and Kroemer G: Anticancer effects of anti-CD47 immunotherapy in vivo. Oncoimmunology 8: 1550619,2019

143. van Panhuys N: TCR signal strength alters T-DC activation and interaction times and directs the outcome of differentiation. Front Immunol 7: 6, 2016.

144. Gross S, Erdmann M, Haendle I, Voland S, Berger T, Schultz E, Strasser E, Dankerl P, Janka R, Schliep S, et al: Twelve-year survival and immune correlates in dendritic cell-vaccinated melanoma patients. JCI Insight 2: e91438, 2017.

145. De Sanctis F, Sandri S, Martini M, Mazzocco M, Fiore A, Trovato R, Garetto S, Brusa D, Ugel S and Sartoris S: Hyperthermic treatment at $56^{\circ} \mathrm{C}$ induces tumour-specific immune protection in a mouse model of prostate cancer in both prophylactic and therapeutic immunization regimens. Vaccine 36: 3708-3716, 2018.

146. Mellman I, Coukos G and Dranoff G: Cancer immunotherapy comes of age. Nature 480: 480-489, 2011

147. Constantino J, Gomes C, Falcão A, Cruz MT and Neves BM Antitumor dendritic cell-based vaccines: Lessons from 20 years of clinical trials and future perspectives. Transl Res 168: 74-95, 2016.

148. Tjoa B, Boynton A, Kenny G, Ragde H, Misrock SL and Murphy G: Presentation of prostate tumor antigens by dendritic cells stimulates T-cell proliferation and cytotoxicity. Prostate 28: 65-69, 1996

149. Ning Y, Shen K, Wu Q, Sun X, Bai Y, Xie Y, Pan J and Qi C: Tumor exosomes block dendritic cells maturation to decrease the T cell immune response. Immunol Lett 199: 36-43, 2018 
150. Van den Eertwegh AJ, Versluis J, Van den Berg HP, Santegoets SJ, Van Moorselaar RJA, Van der Sluis TM, Gall HE, Harding TC, Jooss K, Lowy I, et al: Combined immunotherapy with granulocyte-macrophage colony-stimulating factor-transduced allogeneic prostate cancer cells and ipilimumab in patients with metastatic castration-resistant prostate cancer: A phase 1 dose-escalation trial. Lancet Oncol 13: 509-517, 2012.

151. Mikyšková R, Štěpánek I, Indrová M, Bieblová J, Šímová J, Truxová I, Moserová I, Fučíková J, Bartůňková J, Špíšek R and Reiniš M: Dendritic cells pulsed with tumor cells killed by high hydrostatic pressure induce strong immune responses and display therapeutic effects both in murine TC-1 and TRAMP-C2 tumors when combined with docetaxel chemotherapy. Int J Oncol 48: 953-964, 2016.

152. Neves BM, Cruz MT, Francisco V, Garcia-Rodriguez C, Silvestre R, Cordeiro-da-Silva A, Dinis AM, Batista MT, Duarte CB and Lopes MC: Differential roles of PI3-kinase, MAPKs and NF-kappaB on the manipulation of dendritic cell $\mathrm{T}(\mathrm{h}) 1 / \mathrm{T}(\mathrm{h}) 2$ cytokine/chemokine polarizing profile. Mol Immunol 46: 2481-2492, 2009.

153. Budai Z, Ujlaky-Nagy L, Kis GN, Antal M, Bankó C, Bacsó Z, Szondy $Z$ and Sarang $Z$ : Macrophages engulf apoptotic and primary necrotic thymocytes through similar phosphatidylserine-dependent mechanisms. FEBS Open Bio 9: 446-456, 2019.

154. Bolean M, Borin IA, Simão AMS, Bottini M, Bagatolli LA, Hoylaerts MF, Millán JL and Ciancaglini P: Topographic analysis by atomic force microscopy of proteoliposomes matrix vesicle mimetics harboring TNAP and AnxA5. Biochim Biophys Acta Biomembr 1859: 1911-1920, 2017

155. Cai Y, Ran W, Zhai Y, Wang J, Zheng C, Li Y and Zhang P Recent progress in supramolecular peptide assemblies as virus mimics for cancer immunotherapy. Biomater Sci 8: 1045-1057, 2020.

156. He J, Yin Y, Luster TA, Watkins L and Thorpe PE: Antiphosphatidylserine antibody combined with irradiation damages tumor blood vessels and induces tumor immunity in a rat model of glioblastoma. Clin Cancer Res 15: 6871-6880, 2009.

157. Bondanza A, Zimmermann VS, Rovere-Querini P, Turnay J, Dumitriu IE, Stach CM, Voll RE, Gaipl US, Bertling W, Pöschl E, et al: Inhibition of phosphatidylserine recognition heightens the immunogenicity of irradiated lymphoma cells in vivo. J Exp Med 200: 1157-1165, 2004.

158. Hodge JW, Guha C, Neefjes J and Gulley JL: Synergizing radiation therapy and immunotherapy for curing incurable cancers: Opportunities and challenges. Oncology (Williston Park) 22: 1064-1070, 2008.

159. Guo X, Song J, Zhao J, Wang B, Yang Z, Sun P and Hu M: Impact of ANXA5 polymorphisms on glioma risk and patient prognosis. J Neurooncol 142: 11-26, 2019.

160. Cossarizza A, Cooper EL, Suzuki MM, Salvioli S, Capri M, Gri G, Quaglino D and Franceschi C: Earthworm leukocytes that are not phagocytic and cross-react with several human epitopes can kill human tumor cell lines. Exp Cell Res 224: 174-182, 1996.

161. Pouwels SD, Zijlstra GJ, van der Toorn M, Hesse L, Gras R, Ten Hacken NH, Krysko DV, Vandenabeele P, de Vries M, van Oosterhout AJ, et al: Cigarette smoke-induced necroptosis and DAMP release trigger neutrophilic airway inflammation in mice. Am J Physiol Lung Cell Mol Physiol 310: L377-L386, 2016

162. Kurosaka K, Watanabe $\mathrm{N}$ and Kobayashi Y: Potentiation by human serum of anti-inflammatory cytokine production by human macrophages in response to apoptotic cells. J Leukoc Biol 71: 950-956, 2002.

163. Fischer U, Koppang EO and Nakanishi T: Teleost T and NK cell immunity. Fish Shellfish Immunol 35: 197-206, 2013.
164. Peng B, Liu S, Guo C, Sun X and Sun MZ: ANXA5 level is linked to in vitro and in vivo tumor malignancy and lymphatic metastasis of murine hepatocarcinoma cell. Future Oncol 12: 31-42, 2016.

165. Yang L, Lin S, Kang Y, Xiang Y, Xu L, Li J, Dai X, Liang G, Huang $X$ and Zhao C: Rhein sensitizes human pancreatic cancer cells to EGFR inhibitors by inhibiting STAT3 pathway. J Exp Clin Cancer Res 38: 31, 2019.

166. Gujar SA, Marcato P, Pan D and Lee PW: Reovirus virotherapy overrides tumor antigen presentation evasion and promotes protective antitumor immunity. Mol Cancer Ther 9: 2924-2933, 2010.

167. He D, Li H, Yusuf N, Elmets CA, Li J, Mountz JD and Xu H: IL-17 promotes tumor development through the induction of tumor promoting microenvironments at tumor sites and myeloidderived suppressor cells. J Immunol 184: 2281-2288, 2010.

168. Ma Y, Kepp O, Ghiringhelli F, Apetoh L, Aymeric L, Locher C, Tesniere A, Martins I, Ly A, Haynes NM, et al: Chemotherapy and radiotherapy: Cryptic anticancer vaccines. Semin Immunol 22: 113-124, 2010

169. Hurwitz AA and Watkins SK: Immune suppression in the tumor microenvironment: A role for dendritic cell-mediated tolerization of T cells. Cancer Immunol Immunother 61: 289-293, 2012.

170. Brix K, McInnes J, Al-Hashimi A, Rehders M, Tamhane T and Haugen $\mathrm{MH}$ : Proteolysis mediated by cysteine cathepsins and legumain-recent advances and cell biological challenges. Protoplasma 252: 755-774, 2015.

171. Zhou SL, Zhou ZJ, Hu ZQ, Huang XW, Wang Z, Chen EB, Fan J, Cao Y, Dai Z and Zhou J: Tumor-Associated neutrophils recruit macrophages and T-Regulatory cells to promote progression of hepatocellular carcinoma and resistance to sorafenib. Gastroenterology 150: 1646-1658.e17, 2016.

172. Zhang R and Misra V: Effects of cyclic AMP response element binding protein-Zhangfei (CREBZF) on the unfolded protein response and cell growth are exerted through the tumor suppressor p53. Cell Cycle 13: 279-292, 2014.

173. Liu Z, Noh HS, Chen J, Kim JH, Falo LD Jr and You Z: Potent tumor-specific protection ignited by adoptively transferred CD4+ T cells. J Immunol 181: 4363-4370, 2008

174. Krneta T, Gillgrass A and Ashkar AA: The influence of macrophages and the tumor microenvironment on natural killer cells. Curr Mol Med 13: 68-79, 2013.

175. McCloskey ML, Curotto de Lafaille MA, Carroll MC and Erlebacher A: Acquisition and presentation of follicular dendritic cell-bound antigen by lymph node-resident dendritic cells. J Exp Med 208: 135-148, 2011.

176. Bruno TC: New predictors for immunotherapy responses sharpen our view of the tumour microenvironment. Nature 577: 474-476, 2020

177. Petitprez F, de Reyniès A, Keung EZ, Chen TW, Sun CM, Calderaro J, Jeng YM, Hsiao LP, Lacroix L, Bougoüin A, et al: B cells are associated with survival and immunotherapy response in sarcoma. Nature 577: 556-560, 2020

178. Calorini L and Bianchini F: Environmental control of invasiveness and metastatic dissemination of tumor cells: The role of tumor cell-host cell interactions. Cell Commun Signal 8: 24, 2010.

179. Marinkovic T and Marinkovic D: Biological mechanisms of ectopic lymphoid structure formation and their pathophysiological significance. Int Rev Immunol: Jun 7, 2020 (Epub ahead of print). doi: 10.1080/08830185.2020.1789620.

180. Somersan S, Larsson M, Fonteneau JF, Basu S, Srivastava P and Bhardwaj N: Primary tumor tissue lysates are enriched in heat shock proteins and induce the maturation of human dendritic cells. J Immunol 167: 4844-4852, 2001.

This work is licensed under a Creative Commons Attribution-NonCommercial-NoDerivatives 4.0 International (CC BY-NC-ND 4.0) License. 